Article

\title{
Choline Hydrogen Dicarboxylate Ionic Liquids by X-ray Scattering, Vibrational Spectroscopy and Molecular Dynamics: H-Fumarate and H-Maleate and Their Conformations
}

\author{
Simone Di Muzio ${ }^{1}\left(\mathbb{D}\right.$, Fabio Ramondo ${ }^{2, *}$, Lorenzo Gontrani ${ }^{2}\left(\mathbb{D}\right.$, Francesco Ferella $\left.{ }^{1,3}{ }^{(}\right)$, \\ Michele Nardone ${ }^{1}$ and Paola Benassi ${ }^{1}$ \\ 1 Department of Physical and Chemical Sciences, University of L'Aquila, Via Vetoio, I-67100 L'Aquila, Italy; \\ simone.dimuzio@libero.it (S.D.M.); francesco.ferella@lngs.infn.it (F.F.); michele.nardone@univaq.it (M.N.); \\ paola.benassi@univaq.it (P.B.) \\ 2 Department of Chemistry, University of Rome La Sapienza, P.le A. Moro 5, 00185 Rome, Italy; \\ lorenzo.gontrani@uniroma1.it \\ 3 INFN, Gran Sasso National Laboratories, I-67100 Assergi (AQ), Italy \\ * Correspondence: fabio.ramondo@uniroma1.it
}

Received: 23 September 2020; Accepted: 24 October 2020; Published: 28 October 2020

check for updates

\begin{abstract}
We explore the structure of two ionic liquids based on the choline cation and the monoanion of the maleic acid. We consider two isomers of the anion (H-maleate, the cis-isomer and H-fumarate, the trans-isomer) having different physical chemical properties. H-maleate assumes a closed structure and forms a strong intramolecular hydrogen bond whereas H-fumarate has an open structure. X-ray diffraction, infrared and Raman spectroscopy and molecular dynamics have been used to provide a reliable picture of the interactions which characterize the structure of the fluids. All calculations indicate that the choline cation prefers to connect mainly to the carboxylate group through $\mathrm{OH} \cdots \mathrm{O}$ interactions in both the compounds and orient the charged head $\mathrm{N}\left(\mathrm{CH}_{3}\right)_{3}^{+}$toward the negative portion of the anion. However, the different structure of the two anions affects the distribution of the ionic components in the fluid. The trans conformation of H-fumarate allows further interactions between anions through $\mathrm{COOH}$ and $\mathrm{CO}_{2}^{-}$groups whereas intramolecular hydrogen bonding in H-maleate prevents this association. Our theoretical findings have been validated by comparing them with experimental X-ray data and infrared and Raman spectra.
\end{abstract}

Keywords: ionic liquids; structure; molecular dynamics; X-ray diffraction; vibrational spectroscopy

\section{Introduction}

Protic Ionic Liquids (PILs) [1] are an important subset of the broad class of materials, called ionic liquids (ILs) [2-7], developed and studied in the last 20 years for a variety of applicative issues [8]. PILs are easily obtained by simple acid-base reactions; the resulting salt is usually liquid at room temperature or more generally below $100{ }^{\circ} \mathrm{C}$. PILs with biodegradable and toxicological properties (BiolLs) [9-11] have been developed, combining choline cations (Ch) with amino acid anions [12-17] or a large variety of carboxylic acids of natural origin [11,18,19]. The properties and applications of ionic liquids consisting of choline cations and carboxylate anions have been the subject of a wide number of studies [18] and their structures have been investigated by experiments and theories [20-22]. Despite the chemical simplicity of their synthesis, PILs show quite a complex structure where interactions between molecular constituents include hydrogen bonding along with long-range Coulombic and short-range van der Waals forces. The fundamental role of hydrogen 
bonding in determining the structure of BioILs has been shown in a series of systems where a choline cation is combined with amino acid anions [23-26]. Infrared and Raman spectra and X-ray studies on some choline-based BioILs coupled with carboxylate anions have been reported and their structures have been determined by classical and ab initio molecular dynamics [20-22]. Moreover, vibrational spectroscopy has been largely applied to investigate hydrogen bonding and its dynamic aspects in liquids, starting from pure water $[27,28]$. Among the choline-based BiolLs, our group studied a carboxylate anion, salicylate, which is able to form strong intramolecular hydrogen bonding [22]. X-ray scattering, vibrational spectroscopy and molecular dynamics indicated that the carboxylate group is connected to choline by an $\mathrm{OH}$ group and simultaneously forms an intramolecular hydrogen bond with the $\mathrm{OH}$ group bonded to the benzene ring.

The aim of the present study is to elucidate the role of intramolecular hydrogen bonding in two BioILs constituted by the choline cation [Ch] coupled with the monoanionic maleic acid [H-maleate] and choline coupled with the monoanionic fumaric acid [H-fumarate]. H-maleate and $\mathrm{H}$-fumarate are two isomers (cis and trans) of the $\mathrm{HOOC}-\mathrm{CH}=\mathrm{CH}-\mathrm{CO}_{2}^{-}$anion. The cis-conformation (H-maleate) allows the formation of intramolecular hydrogen bonding whereas the trans-conformation (H-fumarate) hinders any intramolecular interaction. This structural difference affects the physical chemical properties of the respective choline ILs. The melting point of [Ch][H-maleate] $\left(25^{\circ} \mathrm{C}\right)$ is lower than [Ch][H-fumarate] $\left(80^{\circ} \mathrm{C}\right)$ [11], whereas, among the choline-based BioILs analyzed by Fukaya et al. [11], [Ch][H-maleate] was found to have the lowest viscosity value at room temperature. Both the properties have been interpreted as being due to the presence of intramolecular hydrogen bonding in H-maleate that weakens the electrostatic interactions with the cation. Consistently, the Kamlet-Taft parameters measured for some choline dicarboxylate monoanion ILs [11] revealed that the intramolecular hydrogen bond of [Ch][H-maleate] reduces the proton-accepting nature of the hydrogen maleate anion and weakens the hydrogen bond.

Intramolecular hydrogen bonding in H-maleate has also been observed in the gas phase [29] and in the crystal phase [30-32]. In particular inelastic neutron scattering [30], infrared spectroscopy and computational studies [31,32] indicated that the intramolecular hydrogen bond in H-maleate crystal is very strong and symmetric and, moreover, the intramolecular proton transfer potential is extremely shallow. In the present work, we want to compare the structure of the [Ch][H-maleate] and [Ch][H-fumarate] liquids through a combination of X-ray diffraction, infrared and Raman spectroscopy and molecular dynamics (MD) studies. The aim of this study is to evaluate if the different conformation of the $\mathrm{H}$-fumarate and $\mathrm{H}$-maleate anions can really affect the microscopic structure of the liquid.

\section{Materials and Methods}

\subsection{Experimental Details}

\subsubsection{Synthesis}

Choline hydroxide solution (46 wt.\% in $\mathrm{H}_{2} \mathrm{O}$, Aldrich (Italy)), maleic acid (99\%, Aldrich) and fumaric acid ( $99 \%$, Aldrich) were the reagents used, without further purification, in the synthesis. Choline maleate was synthesized by dropwise addition of maleic acid to the choline hydroxide solution in a 1:1 ratio, stirring continuously at room temperature and pressure for $12 \mathrm{~h}$. Most of the water in the reaction mixture was removed under reduced pressure, using a rotary evaporator at $70^{\circ} \mathrm{C}$ for $4 \mathrm{~h}$. The mixture was then dried in vacuo, with heating at $70{ }^{\circ} \mathrm{C}$ and stirring for $24 \mathrm{~h}$. The same procedure was followed for the synthesis of choline fumarate by adding fumaric acid to the choline hydroxide solution. The purity of these BioILs was checked by ${ }^{1} \mathrm{H}-\mathrm{NMR}$ and ${ }^{13} \mathrm{C}-\mathrm{NMR}$ spectroscopy, using a Bruker Avance III spectrometer operating at $400 \mathrm{MHz}$ and $100.6 \mathrm{MHz}$, respectively. The spectra have confirmed the absence of any major impurities and the water final content, evaluated by ${ }^{1} \mathrm{H}-\mathrm{NMR}$ analysis, has been estimated to be below $0.4 \mathrm{wt} . \%$. 


\subsubsection{X-ray Scattering}

X-ray diffraction experiments were carried out with an energy-dispersive instrument that exploits the dependence of diffracted intensity on the energy of the radiation (EDXD—Energy-Dispersive X-ray Diffraction). More details on this method can be found in the supporting information and in previous papers [33-37], where the technique has been successfully employed in the study of non-crystalline systems (liquids, amorphous), and particularly to investigate the structure of ionic liquids [38]. In summary, the outcome of an EDXD experiment consists of a wide $q$-ranging structure factor and total radial distribution patterns that are related to the structural correlations existing among the particles of the system, and that can be modelled and interpreted using analogous patterns built from pairwise distribution functions $(g(r))$ obtained from simulations, like molecular dynamics.

\subsubsection{Infrared and Raman Spectra}

Fourier transformed infrared (FTIR) spectra were measured at room temperature from 4000 to $400 \mathrm{~cm}^{-1}$ after 100 scans using the Perkin Elmer Spectrum two FT-IR spectrometer. Liquid samples were placed as thin films between $\mathrm{KBr}$ plates. Raman spectra were measured using a LABRAM confocal microscope Raman spectrometer by HORIBA Jobin Yvon using $5 \mathrm{~mW}$ at a 632-nm excitation source and a $20 \times$ collection optics. The instrumental resolution is of the order of $2-3 \mathrm{~cm}^{-1}$. Background fluorescence has been fitted using a polynomial expression and subtracted from the data.

\subsection{Computational Details}

The structure of the ionic liquids has been investigated following two theoretical approaches. Local structural ion pairs, with particular attention to the hydrogen bonding interaction, was characterized initially by ab initio methods. Quantum mechanical (QM) calculations on the [Ch][H-fumarate] and [Ch][H-maleate] ion pairs were performed using the Gaussian 09 package [39]. Equilibrium geometry and vibrational frequencies were obtained using density functional theory (DFT) methods with the B3LYP $[40,41]$ exchange and correlation functional and employing the $6-311++G^{* *}$ basis set. The vibrational modes of the isolated ions and ion pairs have been assigned by the analysis of the Potential Energy Distribution (PED) using the VEDA software [42]. The good accuracy of such a functional in predicting the geometries of several organic molecules [43] and energetic properties of ionic liquid clusters [44] has been largely discussed in previous studies. Moreover, the stability and geometries of the most stable ion pairs were further studied at the MP2/6-311++ $G^{* *}$ level to evaluate the accuracy of the functional used for the DFT calculations in our systems.

Dynamic effects were introduced at ab initio level by Ab Initio Molecular Dynamics (AIMD) simulations performed on a model of 10 ion pairs using the Born-Oppenheimer Molecular Dynamics (BOMD) method implemented in the CP2K code [45]. Potential energy calculations were carried out using the BeckeLeeYangParr exchange correlation functional (BLYP) [41,46] and the hybrid Gaussian and plane wave (GPW) basis set. The Gaussian basis set was double zeta valence plus polarization functions optimized for molecular calculations at short range (DZVP-MOLOPT-SR) and the plane wave expansion was developed in a periodic cubic system with a unit cell edge of $15 \AA^{3}$ and truncated at 320 Ry. Goedecker-Teter-Hutter (GTH) pseudopotentials [47,48] were employed to describe core electrons. A pre-equilibration was performed by employing classical molecular dynamics within periodic boundary conditions using the two-body Generalized Amber Force Field (GAFF)[49]. AIMD simulations started from an initial configuration of the classical MD simulation and the system was equilibrated for $6.3 \mathrm{ps}$ in the NVT ensemble at $300 \mathrm{~K}$ using the individual thermostat for each degree of freedom for the first 3 ps and a global Nosé-Hoover chain thermostat [50-52] for the remaining time. The timestep was set to $0.4 \mathrm{fs}$. The trajectory was then collected for $15 \mathrm{ps}$ in the NVT ensemble, saving the velocities and coordinates of every step. With the aim of checking the reliability of the AIMD, we calculated the relative energy drift $\left(\mathrm{E}_{\text {drift }}\right)$ of the 'conserved quantity' during the production run. This procedure has been proposed in a previous study [53] on some ionic liquids 
containing highly flexible units like alkyl chains. The slope of the energy drift $\left(6.01 \times 10^{-6}\right.$ a.u. $\left./ \mathrm{fs}\right)$ reveals that the dynamics are stable and the chosen parameters for the thermostat and SCF criteria convergence are appropriate.

In order to provide a full characterization of the liquid structure within the range of radial distances accessible to experiments, we have performed a series of simulations with the previously cited (GAFF) using the Gromacs 2019.6 package [54] as the molecular dynamics engine. Partial atomic charges have been obtained using the Restrained Electrostatic Potential (RESP) method [55] by fitting the electrostatic potential for isolated cations and anions at the equilibrium geometry calculated at the HF / 6-31G* level. The use of the HF / 6-31G* method has been demonstrated to lead to the implicit polarization required in the additive FF model of condensed phase systems, and complies with the rest of the GAFF parameter set, optimized to be compatible with the Cornell et al. families of Amber force fields [56] that implement this charge derivation scheme. Electrostatic interactions were calculated using Particle Mesh Ewald (PME) under periodic boundary conditions and the Linear Constraint Solver (LINCS) algorithm [57] was applied to all bonds involving hydrogen atoms. Cutoff radii for van der Waals and direct-space Ewald interactions were set to $10 \AA$. Parallelization was carried out with a domain decomposition strategy and the Message Passing Interface (MPI) paradigm.

Topology and coordinate files were prepared using the Amber [58] package (Leap) and all the files were then converted to Gromacs format by using the Babel platform. The initial configurations were generated randomly with the software PACKMOL [59], putting 1000 ion pairs into the cubic box with an initial unit cell edge of $100 \AA$. Equilibration consisted of $10^{4}$ minimization cycles, by gradually heating the systems at $550 \mathrm{~K}$ in the NVT ensemble; the structure was then equilibrated by NPT simulations ( $2 \mathrm{~ns})$ to remove structural inhomogeneities. Systems were cooled (400 K) and density was calibrated by long NPT simulations ( $5 \mathrm{~ns}$ ). Subsequently, the systems were simulated in the NVT ensemble for $3.5 \mathrm{~ns}$ with an integration time step of $1 \mathrm{fs}$ and trajectories were collected every 1000 steps.

Structure factors $I(q)$ have been calculated from the molecular dynamics trajectories using the Travis software $[60,61]$. Theoretical $I(q)$ was then multiplied by $q$ and the $q$-dependent sharpening factor $M(q)$ (with nitrogen as the sharpening atom), to obtain a theoretical $q I(q) M(q)$ function comparable to the experimental one. $D(r)$ and Diff $(r)$ were calculated from theoretical $q I(q) M(q)$ functions by Fourier transform from the reciprocal space $(q)$ to the direct one $(r)$ following the procedure adopted for the experimental data and described in the supporting information.

\section{Results and Discussion}

\subsection{QM Ion Pair}

$\mathrm{H}$-fumarate and $\mathrm{H}$-maleate anions and the respective choline cation pairs were preliminarily optimized in vacuo to investigate the equilibrium structures of the isolated anions, the coupling geometries and structural changes due to ionic pairing. H-fumarate and $\mathrm{H}$-maleate anions differ in the configuration of the $\mathrm{C}=\mathrm{C}$ double bond. The equilibrium structure of the trans-isomer, $\mathrm{H}$-fumarate (Figure 1a), is nonplanar with the carboxylate group $\mathrm{CO}_{2}$ and nearly orthogonal to the $\mathrm{CH}=\mathrm{CHCO}_{2} \mathrm{H}$ moiety. The negative charge is delocalized on the whole carboxylate group with $\mathrm{CO}$ bond distances (1.254 and $1.247 \AA$ ) and an OCO angle $\left(130.5^{\circ}\right)$ typical of the $\mathrm{CO}_{2}^{-}$group. The cis-configuration of the $\mathrm{CO}_{2}^{-}$and $\mathrm{CO}_{2} \mathrm{H}$ groups in $\mathrm{H}$-maleate allows the formation of a seven-membered ring for the formation of a strong intramolecular hydrogen bond (Figure $1 \mathrm{~b}$ ). The $\mathrm{O} \cdots \mathrm{HO}$ angle is nearly linear $\left(176.5^{\circ}\right)$ and the intramolecular $\mathrm{O} \cdots \mathrm{H}$ distance is very short at $1.336 \AA$. The $\mathrm{H}$-maleate is $56.5 \mathrm{~kJ} / \mathrm{mol}$ more stable than $\mathrm{H}$-fumarate and intramolecular hydrogen bonding is largely responsible for this stabilization. Figure $1 \mathrm{~b}$ shows that the geometry of the H-maleate anion is nearly symmetric although hydrogen is not equally shared between two oxygen atoms; however, it is well localized on one the two oxygen atoms with an $\mathrm{OH}$ bond distance of $1.094 \AA$. The intramolecular proton transfer barrier has been estimated by optimizing the geometry of the isomer $C_{2 v}$, where the hydrogen atom occupies a symmetric position. This first order saddle point was found only $10 \mathrm{~kJ} / \mathrm{mol}$ above the equilibrium 
structure. This result is largely consistent with previous ab initio[62,63] and experimental [29] studies on $\mathrm{H}$-maleate anions in the gas phase that indicate the free motion of the proton between the oxygen atoms. A rough estimate of the strength of the intramolecular hydrogen bond has been obtained from the study of the conformer of Figure $1 \mathrm{c}$ where $\mathrm{OH}$ and the carboxylate groups have been oriented to avoid any hydrogen bonding. This open structure was found to be $77.4 \mathrm{~kJ} / \mathrm{mol}$ above the ring equilibrium structure. Our estimate is comparable with the value $(90 \mathrm{~kJ} / \mathrm{mol})$ obtained previously for the H-maleate anion in gas phase with the combined study of photoelectron spectroscopy and ab initio calculations [29]. This means that H-maleate in the gas phase assumes quite a rigid structure where intramolecular hydrogen bonding strongly hinders alternative orientations of the $\mathrm{OH}$ group.
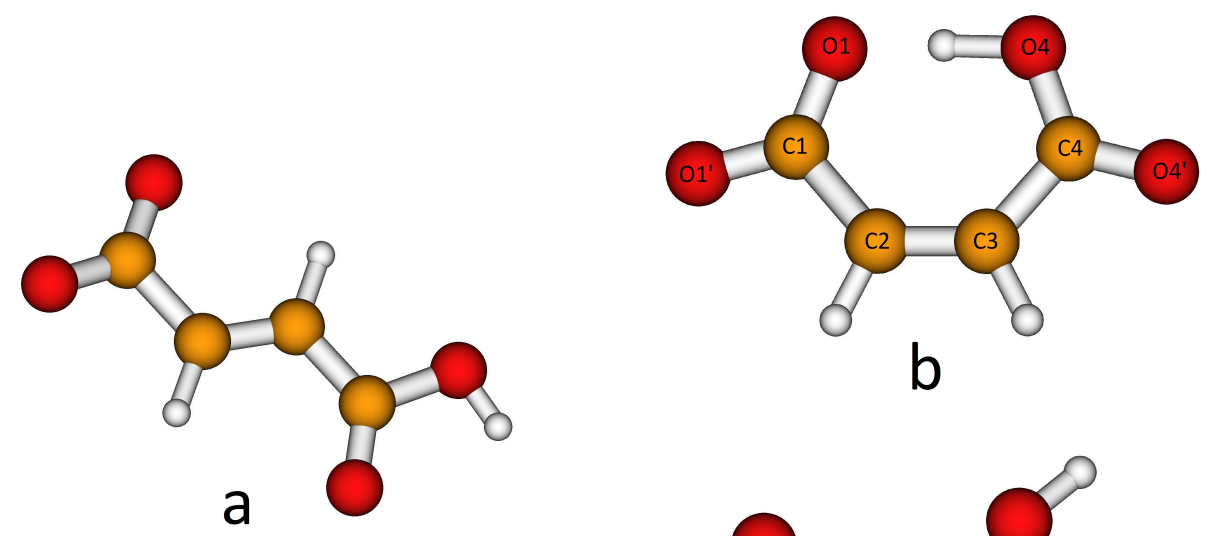

b

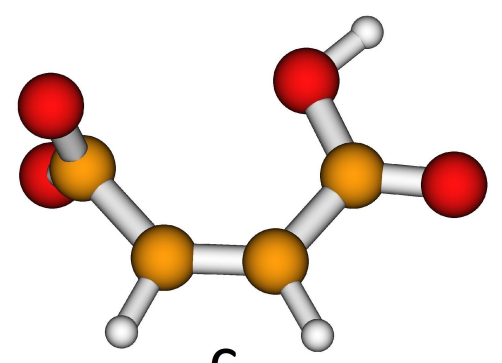

C

Figure 1. Equilibrium structures of the H-fumarate (a) and $\mathrm{H}$-maleate (b) anions and open structure of the H-maleate anion (c).

The structural features of the isolated anions have then been investigated in the presence of the choline cation. The electrostatic potential surface of choline reveals that cations could interact with anions through the $\mathrm{OH}$ group, a hydrogen bonding site, as well as through the $\mathrm{N}\left(\mathrm{CH}_{3}\right)_{3}^{+}$group, a Coulombic interaction site. Previous studies on choline carboxylate anions [20-22] showed that the strong $\mathrm{OH}$... O hydrogen bonding between the choline and carboxylate group is a fundamental feature to describe the interactions between the ionic components in the liquid phase. In the case of hydrogen dicarboxylate anions, the choline cation could interact alternatively with the carboxylic group, again leading to hydrogen bonding. In the case of $\mathrm{H}$-fumarate, both the interactions $\mathrm{CO}_{2} \mathrm{H} \cdots \mathrm{HO}$ and $\mathrm{CO}_{2}^{-} \cdots \mathrm{HO}$ have been considered here and two structures were localized on the potential energy surface for each interaction. Figure $2 \mathrm{a}, \mathrm{b}$ show the geometries optimized when coupling involves the $\mathrm{CO}_{2}^{-} \cdots \mathrm{HO}$ groups, whereas Figure $2 \mathrm{c}$, d reproduce the ion pairs formed through $\mathrm{CO}_{2} \mathrm{H} \cdots$ $\mathrm{HO}$ interactions. The binding energies of the ion pair, estimated as the difference between the energy of the complex and the sum of the energies of the cation and anion, are reported in Figure 2. The first result emerging from the calculations is that choline prefers to interact with the carboxylate group than with the carboxylic group; in addition, the coordination is energetically equivalent for the two oxygen atoms of $\mathrm{CO}_{2}^{-}$. As a comparison, we report the geometries and binding energies for the most stable structure of the ion pair, as obtained by the MP2/6-311++ ${ }^{* *}$ level. The results reproduced in Figure 2 indicate that the structural features of the ion pairs obtained at the B3LYP $/ 6-31++\mathrm{G}^{* *}$ 
level are substantially maintained at the MP2 level. The second important observation is that the binding energies are very large, although the complex formation involves the formation of a single hydrogen bond. This high stabilization could be due to the fact that the binding energy presented here includes all the intermolecular interactions, like hydrogen bonding, Coulombic effects and weaker $\mathrm{CH}$... O dipolar interactions. In all the coordination structures of Figure 2, we in fact observe the presence of these $\mathrm{CH} \cdots \mathrm{O}$ contacts. This structural feature is due to the tendency to orient the charged head $\mathrm{N}\left(\mathrm{CH}_{3}\right)_{3}^{+}$of the choline cation towards the negative charged carboxylate group of the anion. The cation-anion arrangement in isolated ion pairs therefore allows us to maximize all the intermolecular interactions starting from the highly directional $\mathrm{OH} \cdots \mathrm{O}$ hydrogen bonding to the electrostatic Coulombic interactions between the charged portions $\mathrm{N}\left(\mathrm{CH}_{3}\right)_{3}^{+}$and $\mathrm{CO}_{2}^{-}$of the ions ending up to the weaker $\mathrm{CH} \cdots \mathrm{O}$ dipolar interactions. In order to estimate the role of the Coulombic effect on the stability of the complex, additional calculations were carried out on a system where $\mathrm{H}$-fumarate is coupled with a neutral molecule, $\mathrm{N}$, N-dimethylaminoethanol $\left(\mathrm{CH}_{3}\right)_{2} \mathrm{NCH}_{2} \mathrm{CH}_{2} \mathrm{OH}$. In this complex, we can evaluate the stabilization due to a single hydrogen bond, as for the ion pair, without large contributions derived from electrostatic terms. The stability of such a complex is indeed lower $(62 \mathrm{~kJ} / \mathrm{mol})$, revealing the dominant role of the Coulombic interactions in the formation of the ion pairs.
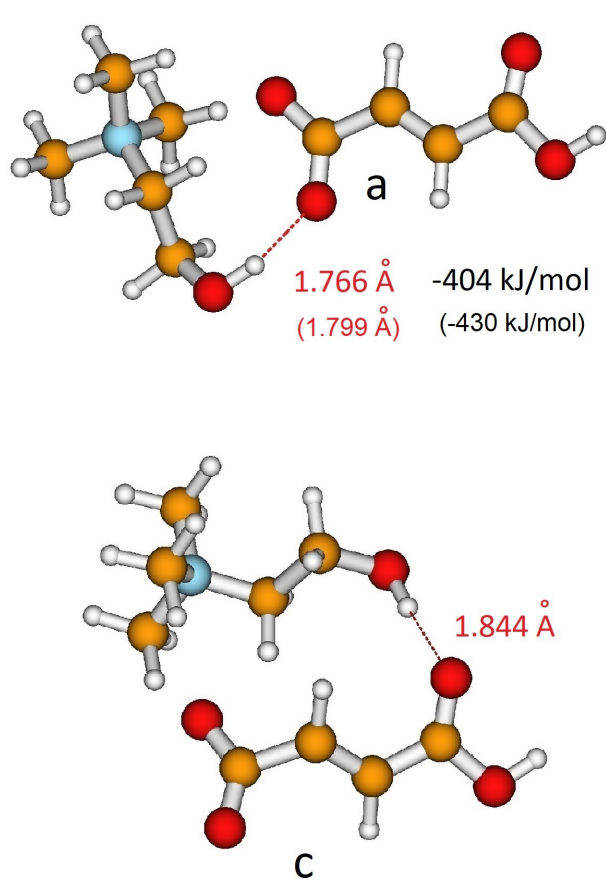

$-369 \mathrm{~kJ} / \mathrm{mol}$

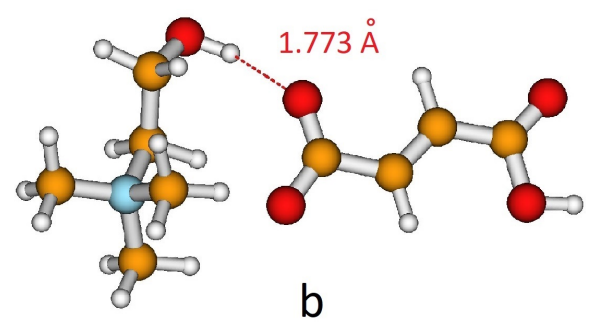

$-403 \mathrm{~kJ} / \mathrm{mol}$

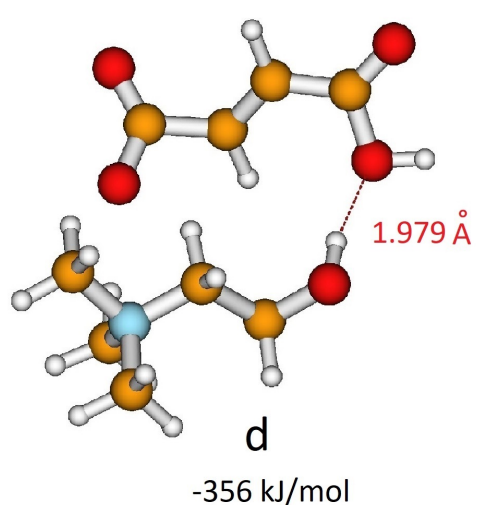

Figure 2. Different coordination structures, (a), (b), (c) and (d), of H-fumarate anion and choline cation. Hydrogen bonding distance and binding energy are evaluated from B3LYP/6-311++ $\mathrm{G}^{* *}$ calculations. Values in parentheses are obtained from MP2/6-311++G** calculations.

As for $\mathrm{H}$-fumarate, as in the case of $\mathrm{H}$-maleate, the ion pairing mainly involves the carboxylate group and the most stable interaction structures are displayed in Figure $3 \mathrm{a}, \mathrm{b}$. The $\mathrm{OH} \cdots \mathrm{O}$ distances suggest that hydrogen bonding in the $\mathrm{H}$-maleate ion pair is similar to that calculated in the $\mathrm{H}$-fumarate ion pair when an interaction occurs with $\mathrm{O1}^{\prime}$, whereas it is weaker when it occurs with O1, the oxygen atom involved in the intramolecular hydrogen bond (for numbering of atoms see Figure 1). Moreover, the interacting geometries suggest that hydrogen bonding in $\mathrm{H}$-fumarate and $\mathrm{H}$-maleate are quite similar, while binding energies calculated for both the structures (Figures 2 and 3) reveal that choline interacts more weakly with $\mathrm{H}$-maleate than $\mathrm{H}$-fumarate and the reason for this is the presence of an 
intramolecular hydrogen bond in H-maleate. In particular, in the trans-conformation of H-fumarate, the negative charge is mainly localized on the carboxylate group and this gives a large dipole moment to the anion $(9.23 \mathrm{D})$. On the contrary, the $\pi$-conjugation through the seven-membered ring allows us to delocalize the negative charge and lower the dipole moment $(3.13 \mathrm{D})$. We expect therefore that the electrostatic component of the binding energy between H-maleate and choline is weaker, as indicated by the values reported in Figure 3. This result is also confirmed at the MP2 level.

As for the isolated anion, the strength of the intramolecular hydrogen bonding of H-maleate has also been investigated in the presence of the choline cation by once again considering the open structure proposed for the isolated anion (Figure 3c). The results obtained suggest that when choline coordinates the carboxylate group, the stability of the intramolecular hydrogen bonding decreases: the open structure was found to be less stable, but the energy difference between the closed and open structure lowers from $77.4 \mathrm{~kJ} / \mathrm{mol}$ for the isolated anion to $38 \mathrm{~kJ} / \mathrm{mol}$ for the coordinated anion. This means that the interaction with choline weakens the intramolecular hydrogen bonding, as also revealed by the value of the $\mathrm{O} \cdots$. H distance, which increases from $1.335 \AA$ to $1.513 \AA$ upon choline coordination.
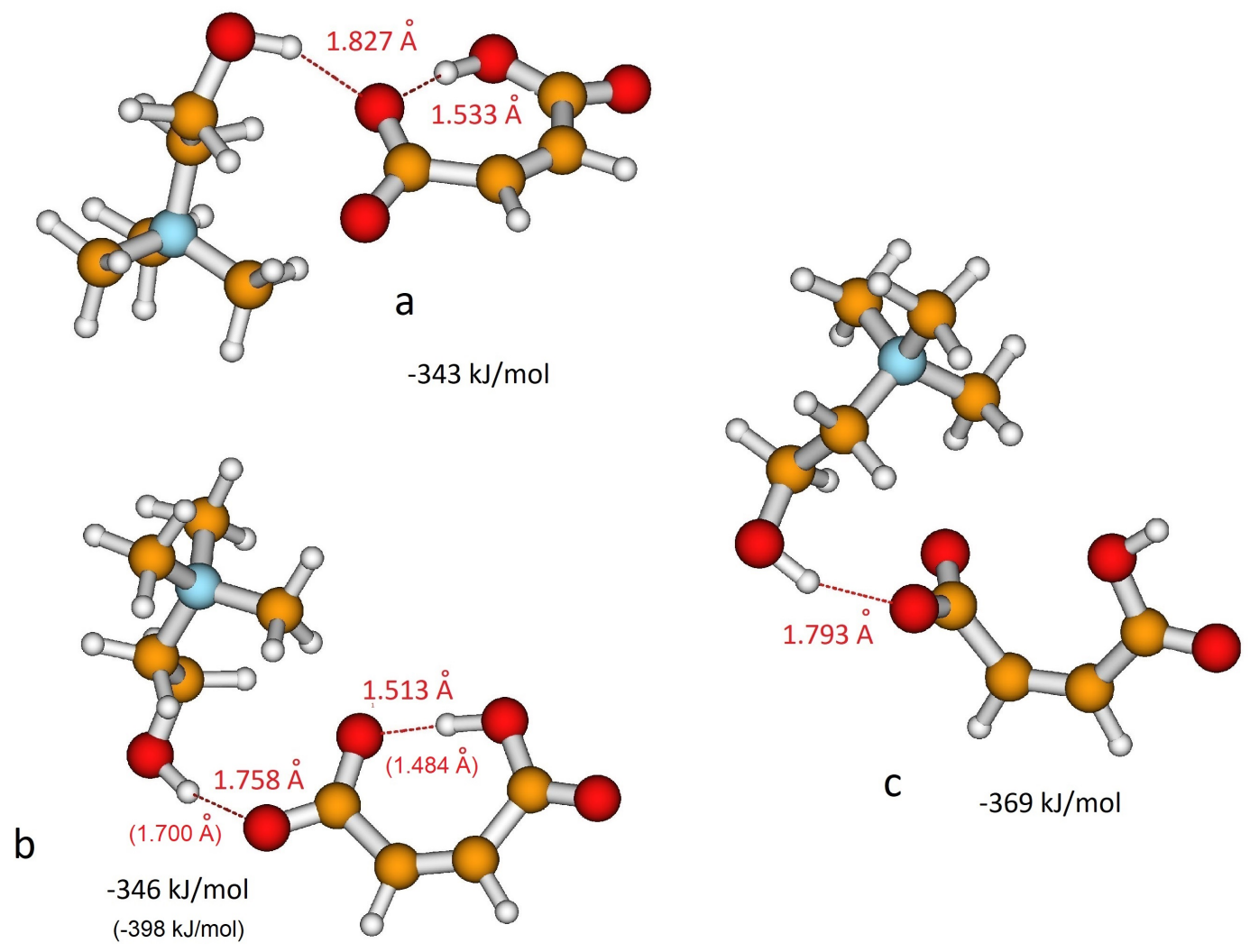

Figure 3. Different coordination structures, (a), (b) and (c), of H-maleate anion and choline cation. Hydrogen bonding distance and binding energy are evaluated from B3LYP/6-311++ $\mathrm{G}^{* *}$ calculations. Values in parentheses are obtained from MP2/6-311++G* calculations.

\subsection{AIMD Results}

The structural features obtained from QM static ionic couples were reconsidered, including the dynamic effects, by AIMD simulations and again with DFT methods. AIMD simulations have been carried out on 10 ion pairs for both the systems. The structure of the anions interacting with choline was initially analyzed through radial distribution functions (RDFs) and dihedral angle distribution functions (DDFs) of some intramolecular geometrical parameters. Conformations of H-fumarate have been considered by the DDFs of the $\mathrm{OH}, \mathrm{CO}_{2}^{-}$and $\mathrm{CO}_{2} \mathrm{H}$ groups, as reproduced in Figure $4 \mathrm{a}, \mathrm{b}$. The curves clearly indicate that $\mathrm{H}$-fumarate has a large conformational freedom; the $\mathrm{OH}$ group 
prefers to assume a syn orientation with respect to the $\mathrm{C}=\mathrm{O}$ bond, whereas the rotation for the carboxylate group is relatively free. On the contrary, the carboxylic group is substantially coplanar with the $\mathrm{C}=\mathrm{C}$ bond.
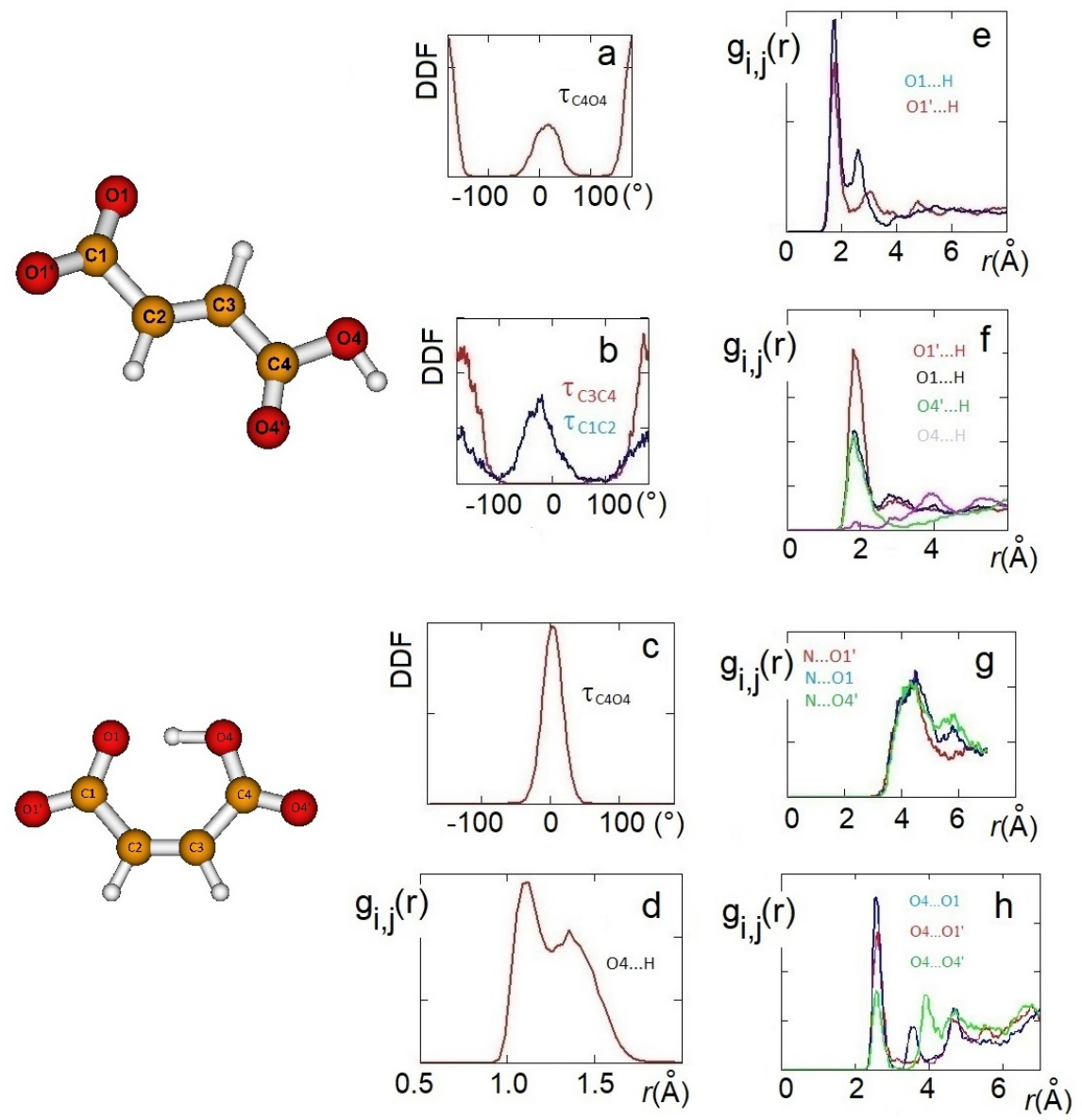

Figure 4. AIMD results: $\mathrm{HO} 4 \mathrm{C} 4 \mathrm{C} 3$ dihedral angle distribution functions (DDFs) of [Ch][H-fumarate] (a) and [Ch][H-maleate] (c); O4C4C3C2 and O1C1C2C3 DDFs of [Ch][H-fumarate] (b). Radial distribution function (RDF) of the intramolecular $\mathrm{O} \cdots \mathrm{H}$ distance in [Ch][H-maleate] (d); RDFs of the $\mathrm{H} \cdots \mathrm{O}$ cation-anion distances in [Ch][H-fumarate] (e) and [Ch][H-maleate] (f); RDFs of the $\mathrm{N} \cdots \mathrm{O}$ cation-anion distances in [Ch][H-maleate] (g); RDFs of the $\mathrm{O} \cdots \mathrm{O}$ anion-anion distances in [Ch][H-fumarate] (h).

As already emerges from the static calculations, H-maleate has, instead, a very rigid conformation, since intramolecular hydrogen bonding deeply affects its dynamic aspects. The DDF of the OH group, reproduced in Figure 4c, shows that the seven-membered ring contains very stable and open structures, similar to those proposed previously, and can be reasonably excluded, at least for the simulation time of our dynamics. Even if hydrogen is mainly covalently bonded to $\mathrm{O} 4$, as it just occurs in the ion pair, during dynamics, we can observe the proton transfer from $\mathrm{O} 4$ to O1. RDF between $\mathrm{O} 4$ and $\mathrm{H}$ has, in fact, two peaks - one at values typical of very strong hydrogen bonds $(1.4 \AA)$ and a second peak at the covalent bond distance of $1.06 \AA$ (Figure $4 \mathrm{~d}$ ).

In order to investigate the morphology of the systems, at least at short range, hydrogen bonding between cations and anions has been monitored through the RDFs between the hydrogen of the choline $\mathrm{OH}$ group and oxygen atoms of the anion. For H-maleate as well as for H-fumarate, the distribution of the intermolecular $\mathrm{O} \cdots \mathrm{H}$ distances indicates that the coordination involves the carboxylate group

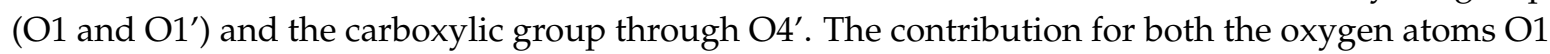
and $\mathrm{O}^{\prime}$ is comparable for H-fumarate (Figure 4e) as a consequence of the fact that the carboxylate group has a nearly symmetric charge distribution. The $\mathrm{O} \cdots \mathrm{H}$ distance is in line with those determined 
for the static ion pair. Some differences are found in the case of H-maleate: the choline cation shows a higher probability to bind $\mathrm{O}^{\prime}$ than $\mathrm{O} 1$ (Figure 4f) since intramolecular hydrogen bonding gives asymmetry to the carboxylate group. In addition, the peaks of the RDFs of H-maleate are slightly larger than those of H-fumarate, in agreement with the fact that hydrogen bonding between cations and anions is less directional when intramolecular hydrogen bonding is formed. Figure $4 \mathrm{~g}$ also shows the RDFs between the nitrogen of choline and the oxygen of the anions. Such RDFs show large peaks at about $4 \AA$. This correlation, quite common in choline carboxylate ionic liquids [20-22], is due to the electrostatic interaction between the negatively charged oxygen atoms of the anions and the $\mathrm{N}\left(\mathrm{CH}_{3}\right)_{3}^{+}$portion of the cations. These additional interactions act as a docking force, determining the local morphology of the ion-ion interaction. On the other hand, the tendency to favourably orient cations and anions to maximize the reciprocal interactions was already found from the structures of the small static ion pairs discussed above. Bearing in mind that our AIMD simulations are too short to give a full description of dynamics of hydrogen bonding, the results obtained clearly show that $\mathrm{H}$-maleate forms intramolecular hydrogen bonds and keeps its closed structure during the time of the dynamics. This structural feature can have an important role in the distribution of the ionic species in the liquid. As normally occurs in ionic liquids, the first neighbor contacts are those between cations and anions and the narrow distribution of $\mathrm{O} \cdots \mathrm{H}$ values at about $1.8 \AA$ provides clear evidence that cations and anions form strong hydrogen bonds through carboxylate and carboxylic groups. One interesting aspect emerges when we analyse the anion-anion distribution distances in the two systems. In the trans-conformation, $\mathrm{H}$-fumarate can establish hydrogen bonds between $\mathrm{CO}_{2}^{-}$and $\mathrm{COOH}$ groups, as shown by the RDF O . . O distances reproduced in Figure 4h. The structure of [Ch][H-fumarate] liquid should be therefore characterized by a complex pattern: part of the anions are strongly coupled with cations by electrostatic and hydrogen bonding; on the other hand, the presence of donor acceptor sites on the anions makes them able to interact with each other by hydrogen bonds. No correlation between anions was found for [Ch][H-maleate] since intramolecular hydrogen bonding hinders any interaction between anions. Similarly, no correlation was found between choline cations.

\subsection{X-ray Results and MD Simulations}

Since our AIMD models are clearly too small to provide long range structural features and the application of ab initio molecular dynamics on systems larger than those proposed here is still prohibitive, the [Ch][H-maleate] and [Ch][H-fumarate] liquids were investigated through classical molecular dynamics. Despite classical force fields not always accurately describing protic ionic liquids $[21,64,65]$, we decided to use the GAFF force field anyway since it covers almost all the organic species without the need for further parametrization and it gave good results for some systems like choline salicylate liquid [22]. As discussed for the AIMD results, the structure of our liquids was analyzed by monitoring some important intermolecular distances, starting from the hydrogen bond ones. The presence of strong hydrogen bonding between the choline and oxygen atoms of the anions is confirmed by the classical simulations. RDFs of the $\mathrm{H} \cdots$ O contacts reproduced in Figure 5a,b indicate that the interaction mainly involves the carboxylate group and, to a lesser extent, also the O4' atom of the carboxylic group. A remarkable difference between ab initio and classical models is the fact that the $\mathrm{O} 1$ and $\mathrm{O}^{\prime}$ atoms of the carboxylate group are equally bonded to choline both in H-fumarate (Figure 5a) and H-maleate (Figure 5b). Thus, the small asymmetry in the hydrogen bonding acceptor properties of the carboxylate oxygen of H-maleate emerging from ab initio results is not appreciable from the classical force field. The equivalence of the two hydrogen bonds is consistent with the fact that the force field here applied describes the carboxylate group with nearly symmetric interaction potentials. The structure of the liquids presents an alternating pattern of anions and cations, as witnessed by the structured peak in the N . . O intermolecular RDF at about $4 \AA$ (Figure 5c,d). For both the systems, the $\mathrm{CO}_{2}^{-}$group coordinates the cationic charged head $\mathrm{N}\left(\mathrm{CH}_{3}\right)_{3}^{+}$better than $\mathrm{COOH}$ for stronger electrostatic effects. It is interesting to note that the coordination of the $\mathrm{N}\left(\mathrm{CH}_{3}\right)_{3}^{+}$portion to the anion leads to the formation of $\mathrm{CH}$. . O contacts with all the oxygen atoms and Figure 5e 
shows the RDFs of one of the hydrogen atoms of the methyl groups with all the oxygen atoms of the H-maleate anion.

It is worth noting that the anion-anion distribution is different for the two liquids, as already found from our AIMD simulations. Figure $5 \mathrm{f}$ confirms that, in [Ch][H-fumarate] liquid, in addition to the alternation of cations and anions, anion-anion interactions driven by hydrogen bonding between $\mathrm{CO}_{2}^{-}$and $\mathrm{COOH}$ groups are expected. Such structural feature can instead be excluded in the $[\mathrm{Ch}][\mathrm{H}$-maleate] system.
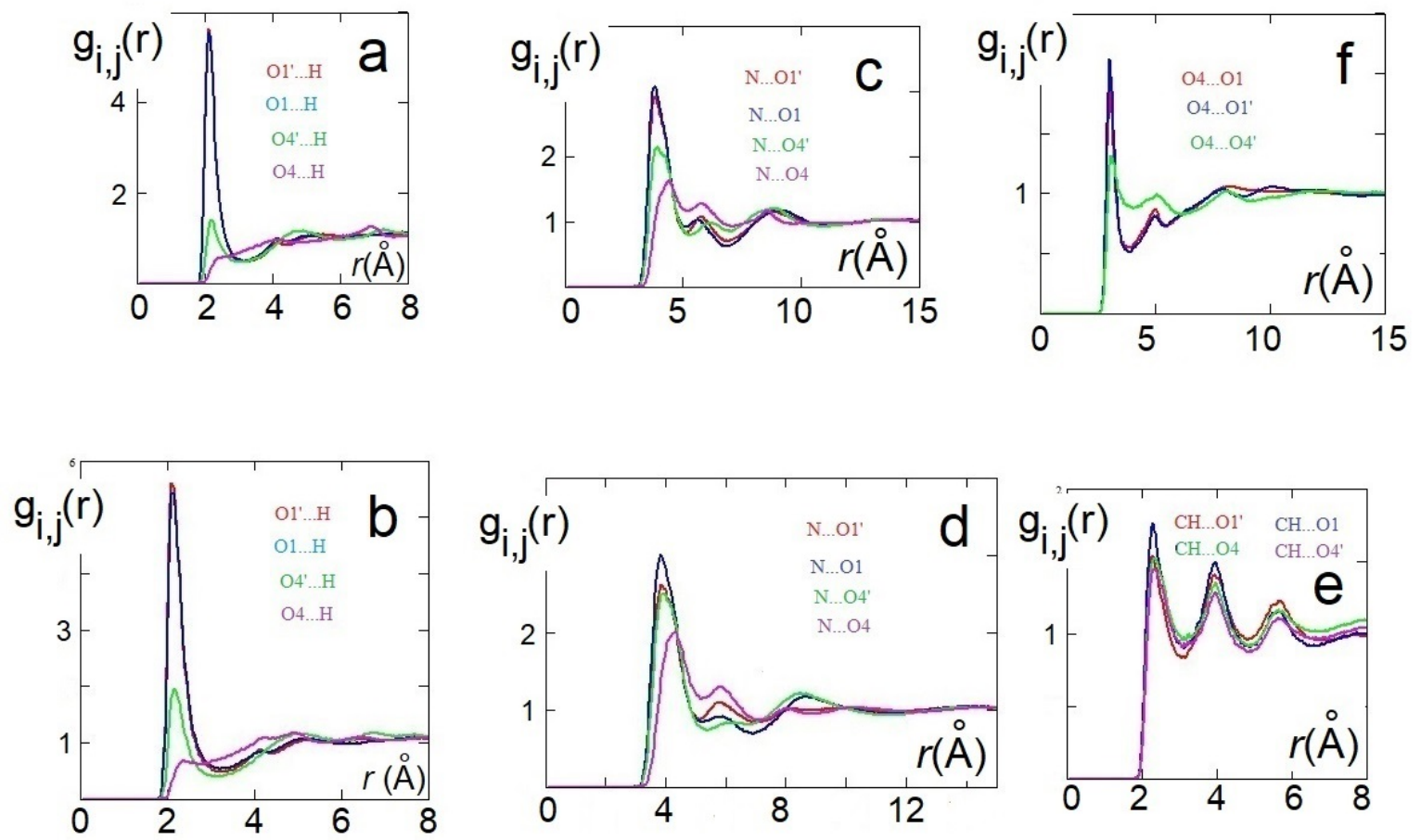

Figure 5. RDFs of the $\mathrm{H} \cdots \mathrm{O}, \mathrm{N} \cdots \mathrm{O}$ and $\mathrm{CH} \cdots \mathrm{O}$ cation anion distances in [Ch][H-fumarate] $(\mathbf{a}, \mathbf{c}, \mathbf{e})$ and [Ch][H-maleate] (b and $\mathbf{d}$ ); RDFs of the $\mathrm{O} \cdots \mathrm{O}$ anion-anion distance in [Ch][H-fumarate] (f) from classical molecular dynamics (MD) simulations.

The structure of the two liquids has been studied experimentally through X-ray diffraction and, in Figure 6, we report the X-ray structure function of each system (upper panel) and the complementary Diff( $r$ ) function (lower panel). The interpretation of the diffraction pattern is not easy since the experimental data are the averaged results of all the inter-atomic and intra-atomic distances of the systems. In addition, the comparison between the two systems shows that the curves are indeed very similar. As known, the pattern above $5 \AA^{-1}$ corresponds roughly to intramolecular distances, whereas the intermolecular distances are expected to give rise the peaks below this value. In this region, the principal peak, at about $1.3 \AA^{-1}$, which correlates with distances between 3 and $6 \AA$, is due to the alternating pattern of cations and anions in the liquid. Figure 6 shows that the main peak of $[\mathrm{Ch}][\mathrm{H}$-maleate] is slightly larger and has the maximum at lower $q$ with respect to the [Ch][H-fumarate]. This feature could be due the fact that the closed structure of $\mathrm{H}$-maleate reduces its ability to coordinate cations by hydrogen bonds, giving a less compact liquid structure than $\mathrm{H}$-fumarate. Consistently, the peak at about $6 \AA^{-1}$ occurs at higher $q$ for H-maleate since its closed geometry gives a peak centered at smaller intramolecular distances. These slight differences and the structural features emerging from our MD simulations suggest that the open structure of [Ch][H-fumarate] could give a less structured liquid. 

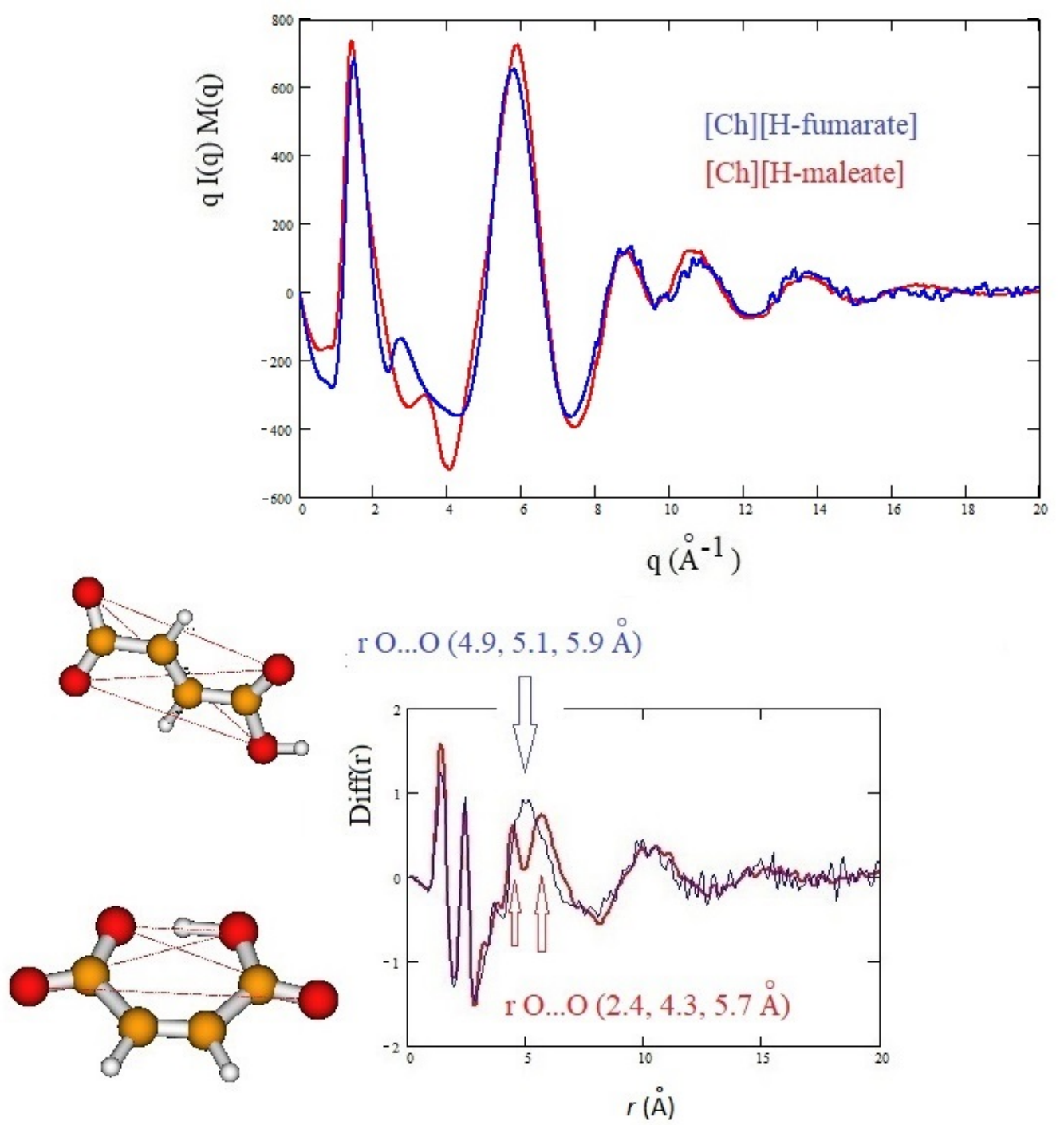

Figure 6. Experimental $q I(q) M(q)$ and Diff(r) curves of [Ch][H-maleate] and [Ch][H-fumarate]; figure shows the intramolecular $\mathrm{O} \cdots \mathrm{O}$ distances calculated from density functional theory (DFT) geometries of the two anions.

The differences are more marked in the shoulder appearing at the right of the main peak: [Ch][H-maleate] shows a peak at about $3.5 \AA^{-1}$, whereas [Ch][H-fumarate] shows one at $2.8 \AA^{-1}$. The first peak correlates with distances at $1.8 \AA$ and the second with contacts at $2.2 \AA$ in the direct space. Such peaks can be due to both inter- and intramolecular distances. Such features are typical of choline carboxylate ionic liquids and have been previously considered as fingerprints of hydrogen bonding interactions [26]. Similarly, the Diff( $r$ ) curves of the two systems show a different pattern, particularly in the region between 4 and $6 \AA$ : [Ch][H-maleate] shows two distinct peaks at $4.4 \AA$ and $5.6 \AA$ whereas [Ch][H-fumarate] shows a wide and single peak around $5 \AA$. One of the reasons for this different pattern could be found in the different conformations of the $\mathrm{H}$-maleate and $\mathrm{H}$-fumarate anions. The presence of two peaks in the [Ch][H-maleate] could be consistent with the distribution of the $\mathrm{O} \cdots \mathrm{O}$ intramolecular distances in the cis-isomer; the anti-conformation instead would give rise to intramolecular distances very similar to each other, as summarized in Figure 6. In addition, strong peaks between 4 and $6 \AA$ might be attributed to cation-anion as well as anion-anion correlations, as indicated by RDFs expected in this region (Figures 4 and 5). Another explanation of these differences could be tentatively found by considering that the anion-anion distribution predicted by MD simulations for [Ch][H-fumarate] 
could produce peaks broader than those observed for [Ch][H-maleate], where the only correlation derives from the alternating cationic-anionic pattern. A validation of the theoretical results here presented can be obtained by comparing the findings from the MD simulation with the measured X-ray diffraction pattern. The results are presented in Figure 7. The agreement between the $q I(q) M(q)$ experimental curves and the same functions calculated from MD simulations is quite good across all $q$ values, with a few minor differences in the region between 3 and $4 \AA^{-1}$. In particular, MD simulations reproduce the shoulders of the main peak well, but introduce a secondary peak at about $4 \AA^{-1}$ for [Ch][H-fumarate] and at $4.8 \AA^{-1}$ for [Ch][H-maleate], which is not present in the experimental curves and that correlate with some intramolecular distances that were not fully reproduced by GAFF force field. It is interesting to observe that the complementary Diff( $r$ ) functions are satisfactory reproduced in both the intra- and intermolecular structural range with some differences in the region of the hydrogen bonding, probably due to the limit of the GAFF force field in reproducing this critical spectral region [21,64]. Another discrepancy is observed in the region of the long distances for [Ch][H-fumarate] where the theoretical curve is quite smooth. This means that our model describes $[\mathrm{Ch}][\mathrm{H}$-fumarate] as a liquid that is less structured than $[\mathrm{Ch}][\mathrm{H}$-maleate] since the alternation between cations and anions may be perturbed by the presence of anion-anion interactions that give a more random distribution of the ionic components. It is likely that our force field overestimates this effect and, consequently, the agreement in this region worsens.
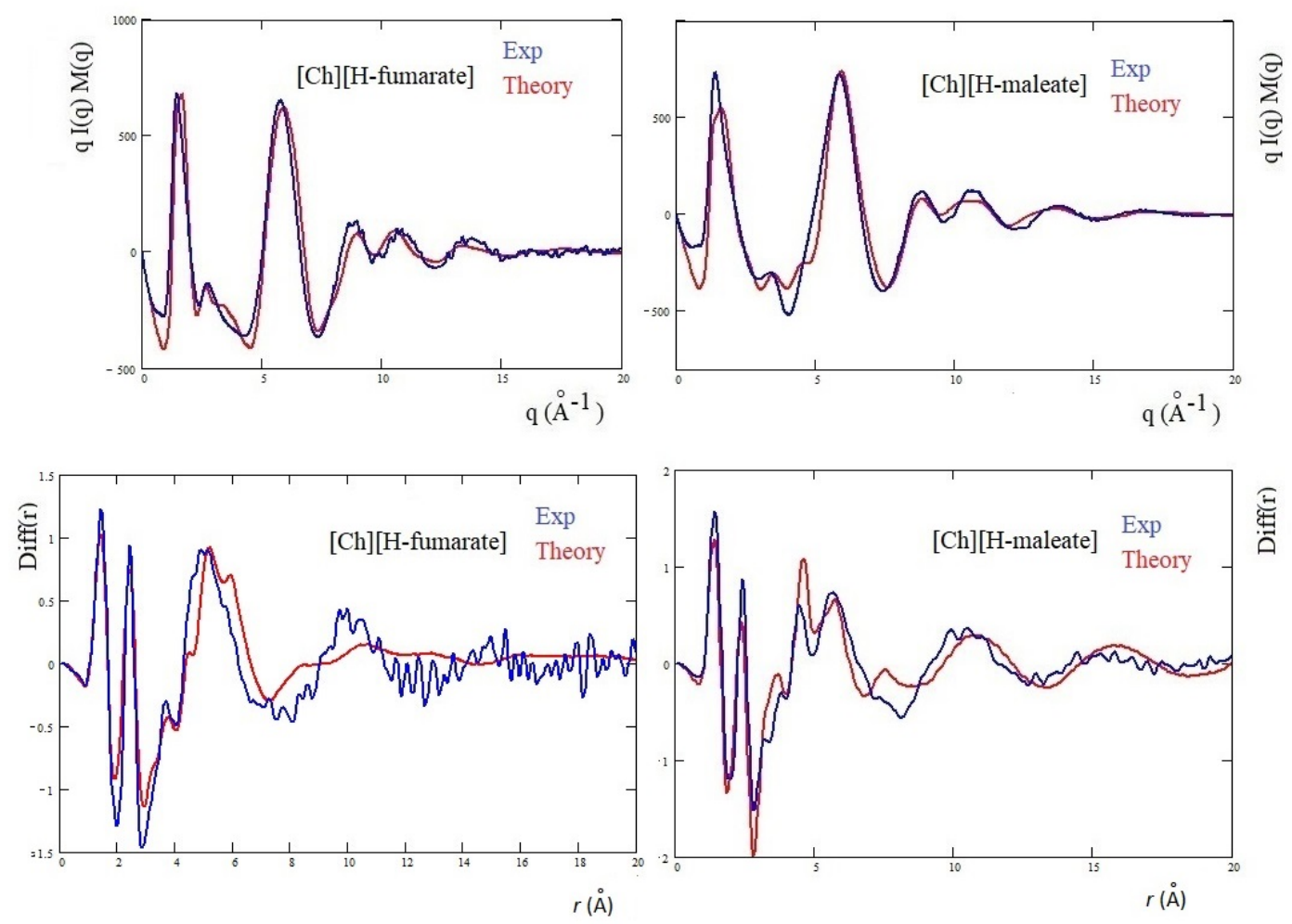

Figure 7. Theoretical $q I(q) M(q)$ and $\operatorname{Diff}(r)$ of H-maleate and H-fumarate in comparison with experiment.

\subsection{IR and Raman Spectra}

The vibrational properties of the two liquids were studied through IR and Raman spectroscopy, whose patterns are shown in Figures 8 and 9. The assignment of the main bands was made on the basis of DFT calculations as well as by considering vibrational properties of choline carboxylate ionic liquids previously measured [20-22]. IR and Raman spectra of the H-fumarate and H-maleate anions, choline cation and the respective ion pairs considered in the most stable structures were calculated at the B3LYP/6-31++G** level. Vibrational modes were analyzed on the basis of the calculated PED and the 
assignments are reported in Tables S1 and S2. Although the theoretical spectra here presented do not actually describe the liquid phase but only ion pairs, the main effect on the vibrational modes due to hydrogen bonds can be estimated from our models anyway. The analysis of the normal modes indicate in fact that the vibrations are mainly localized on each ionic component with coupling indeed being slight and limited to the very low frequency modes. Therefore, it is quite easy to separate the vibrations of the choline cation from those of the anions. In addition, the theoretical spectra show that the choline bands are found to be substantially unchanged in the two ion pairs, suggesting that the coupling effect on the vibration modes of choline is indeed similar in both systems. The observed and calculated frequencies are summarized in Tables 1 and 2. The high-frequency zone of the IR spectra is largely dominated by the broad $\mathrm{OH}$ stretching absorption, with weaker bands originated by the $\mathrm{CH}$ stretching modes. On the contrary, the $\mathrm{CH}$ stretching vibrations are clearly evident in the Raman spectra and give rise to three intense bands, at about 3036, 2980 and $2930 \mathrm{~cm}^{-1}$, assigned to vibrations of the $\mathrm{CH}_{3}$ and $\mathrm{CH}_{2}$ groups of choline and $\mathrm{CH}$ bonds of the anions. The theoretical spectra show that this zone is very similar for the two systems; the only difference is expected for the $\mathrm{OH}$ stretching mode. Its frequency is strongly affected by intramolecular hydrogen bonding and by its strength. For example, in the isolated anion, where the proton is nearly symmetric between the oxygen atoms, this mode is strongly coupled with the CO stretching motions and its frequency is very low $\left(1814 \mathrm{~cm}^{-1}\right)$. In the ion pair, the strength of the intramolecular interaction lowers and the relative frequency increases to $2805 \mathrm{~cm}^{-1}$. This vibration has been measured at $2833 \mathrm{~cm}^{-1}$ in the choline salicylate liquid, where the $\mathrm{OH}$ group of the anion is involved in a strong intramolecular hydrogen bond. However, we are aware that this vibration could be strongly affected by all the interactions that the anions may make in the liquid phase and its frequency is not accurately reproduced by a single ion pair. The IR spectrum of H-maleate shows broad and very weak absorptions in this region that we can hardly assign to this mode.

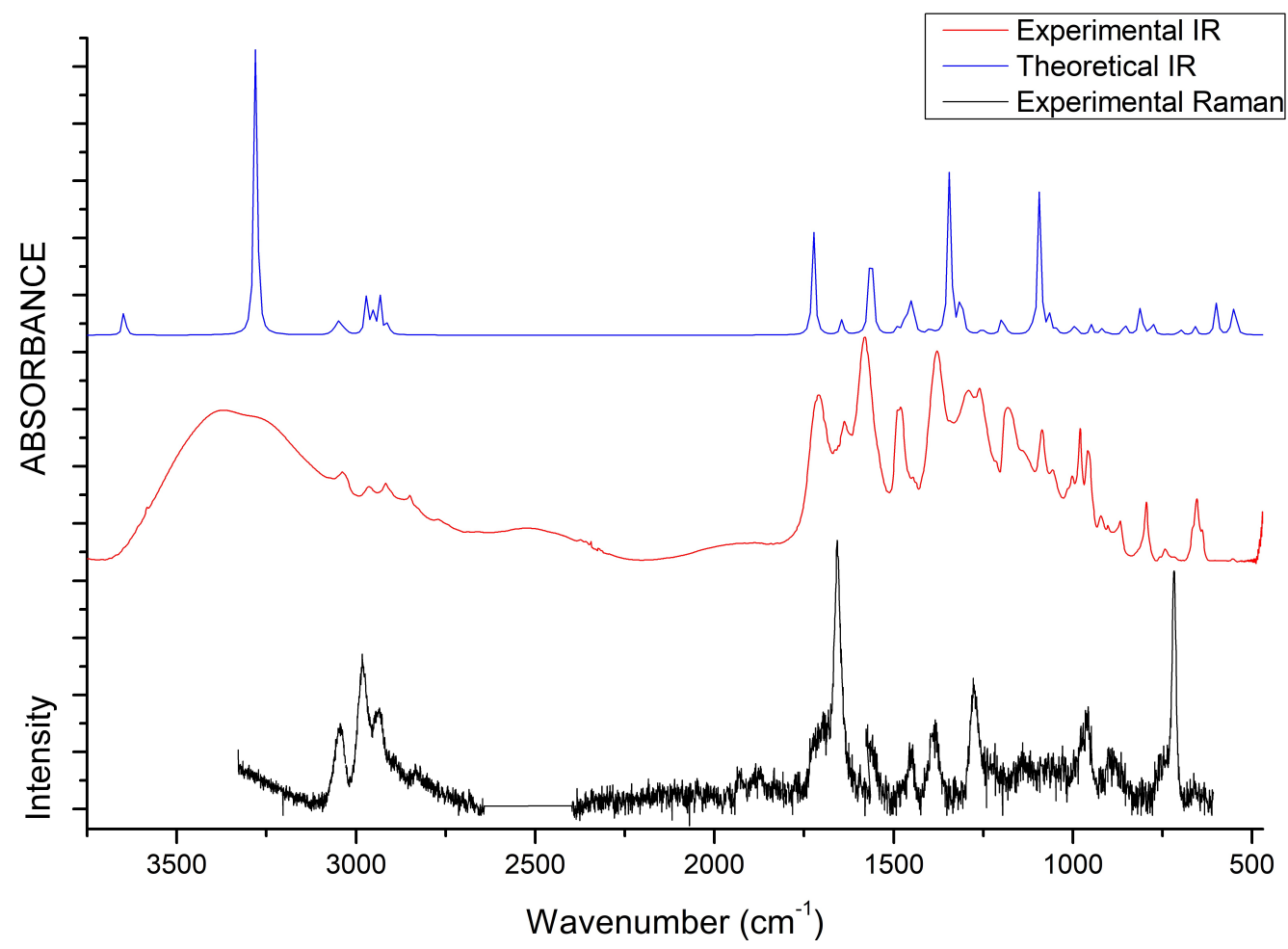

Figure 8. IR and Raman spectra of [Ch][H-fumarate] liquid. B3LYP values are scaled for 0.96 [66]. 


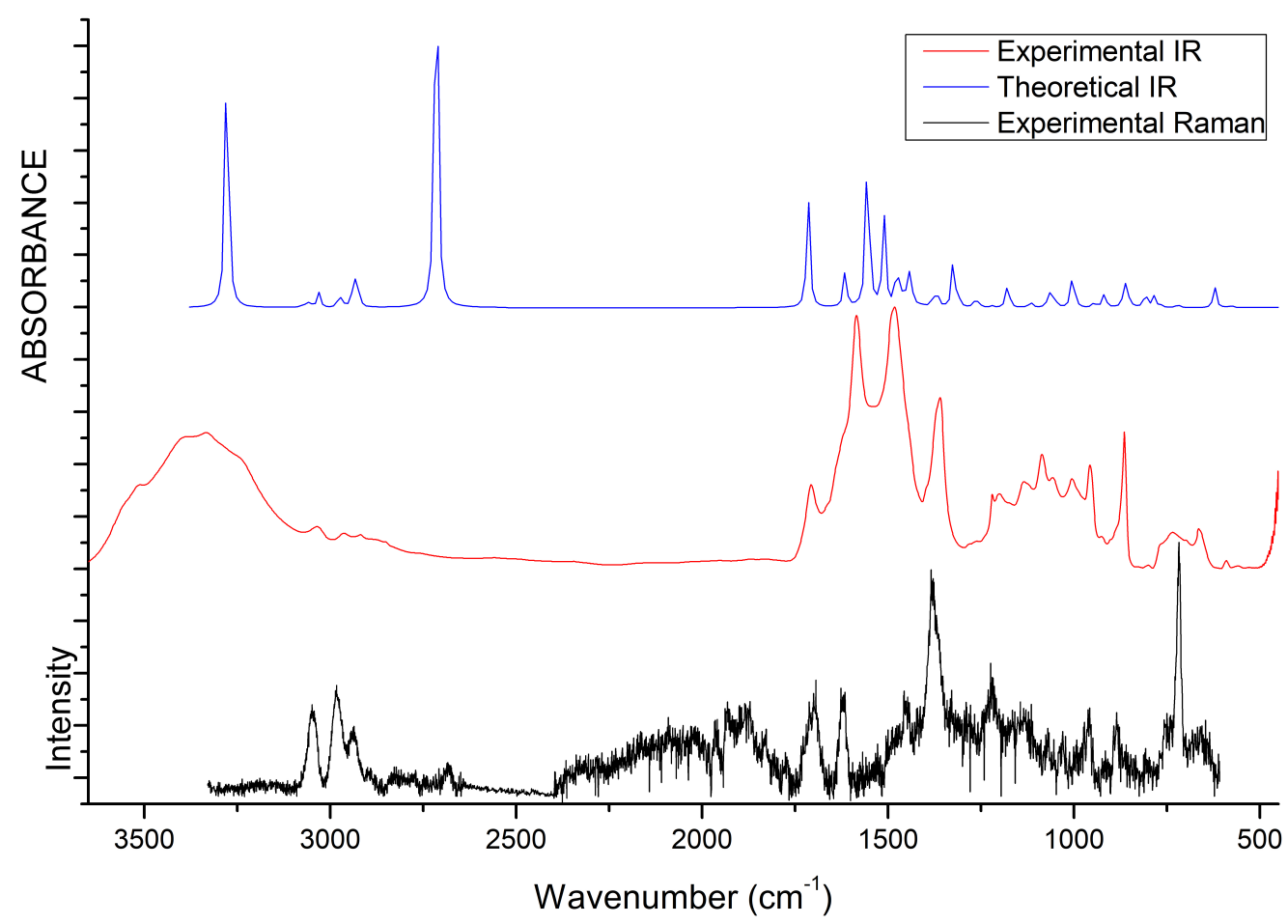

Figure 9. IR and Raman spectra of [Ch][H-maleate] liquid. B3LYP values are scaled for 0.96 [66].

At a lower frequency, we expect the bands of the stretching modes of the $\mathrm{COOH}$ and $\mathrm{CO}_{2}^{-}$groups and the $\mathrm{C}=\mathrm{C}$ bond. The $\mathrm{C}=\mathrm{C}$ stretching vibration gives rise to intense absorptions in the Raman spectra of [Ch][H-fumarate] $\left(1661 \mathrm{~cm}^{-1}\right)$ and [Ch][H-maleate] $\left(1623 \mathrm{~cm}^{-1}\right)$, in agreement with the calculated values at 1698 and $1669 \mathrm{~cm}^{-1}$, respectively. The lower vibrational frequency for the $\mathrm{C}=\mathrm{C}$ bond of $\mathrm{H}$-maleate is expected as a consequence of the intramolecular hydrogen bond: the formation of the seven-membered ring allows for $\pi$-conjugation through the $\mathrm{C}=\mathrm{C}$ bond and the lowering of the relative stretching frequency. Such bands are less intense in the IR spectra and are measured at 1640 and at $1610 \mathrm{~cm}^{-1}$, respectively. The $\mathrm{C}=\mathrm{O}$ stretching mode of the $\mathrm{COOH}$ group is observed at 1706 (IR) and 1700 (Raman) for H-fumarate and at 1712 (IR) and 1694 (Raman) for H-maleate. The C-O stretching mode of the $\mathrm{COOH}$ group can be assigned to the band at $1189 \mathrm{~cm}^{-1}$ for [Ch][H-fumarate], whereas it is not easy to find the relative absorption in the [Ch][H-maleate] spectra.

The stretching vibrations of the $\mathrm{CO}_{2}^{-}$group can be classified as $\mathrm{CO}$ asymmetric and $\mathrm{CO}$ symmetric stretching and the relative bands are observed in the IR spectrum at 1582 and $1389 \mathrm{~cm}^{-1}$ for [Ch][H-fumarate] and 1580 and $1361 \mathrm{~cm}^{-1}$ for [Ch][H-maleate], respectively. The CO symmetric vibrations are measured in the Raman spectrum at $1384 \mathrm{~cm}^{-1}$ for [Ch][H-fumarate] and at $1382 \mathrm{~cm}^{-1}$ for [Ch][H-maleate]; the asymmetric vibration is weaker and absorption is appreciable only for the [Ch][H-fumarate] at $1580 \mathrm{~cm}^{-1}$. It is interesting to note that these two absorptions are measured at frequencies that are very similar in the two anions, as expected from the DFT values calculated for the ion pairs. As known [20], hydrogen bonding can be analyzed also by looking at the stretching frequencies of the $\mathrm{CO}_{2}^{-}$group. An isolated carboxylate group has a symmetric geometry and the extent of coupling between symmetric and asymmetric $\mathrm{CO}$ stretching is high. Hydrogen bonding induces asymmetry in the $\mathrm{CO}_{2}^{-}$structure, lowering the coupling between the two modes. This effect is well summarized by the difference between the asymmetric and symmetric $\mathrm{CO}$ stretching frequencies, $\Delta v \mathrm{CO}$. In the $\mathrm{H}$-fumarate-isolated anion where the carboxylate is free, $\Delta v \mathrm{CO}$ is $297 \mathrm{~cm}^{-1}$, whereas, in the ion pair, where carboxylate forms hydrogen bonding, the frequencies of the two modes approach each other and $\Delta v C O$ lowers to $228 \mathrm{~cm}^{-1}$. A similar value, $239 \mathrm{~cm}^{-1}$, is calculated for the choline $\mathrm{H}$-maleate ion pair where carboxylate is involved in intramolecular as well as intermolecular hydrogen 
bonds. On the basis of our assignments, the $\Delta v \mathrm{CO}$ obtained from the experimental frequencies for [Ch][H-fumarate] $\left(200 \mathrm{~cm}^{-1}\right)$ and [Ch][H-maleate] $\left(200 \mathrm{~cm}^{-1}\right)$ is very similar for the two liquids, suggesting that the carboxylate group is perturbed similarly in both systems.

Some vibrational modes are more sensitive to hydrogen bonding-in particular the in-plane bending, $\delta \mathrm{OH}$, and out-of-plane deformation $\tau \mathrm{OH}-$ of the $\mathrm{OH}$ group. The $\delta \mathrm{OH}$ motion is appreciably coupled with the in-plane bending vibrations of the $\mathrm{CH}$ groups; however, the PED suggests that the band at $1292 \mathrm{~cm}^{-1}$ in the IR spectrum of [Ch][H-fumarate] could be assigned to a mode where the $\delta \mathrm{OH}$ component is prevalent. Intramolecular hydrogen bonding strongly hinders this motion in the choline $\mathrm{H}$-maleate and its frequency is measured at much higher values $\left(1588 \mathrm{~cm}^{-1}\right)$. For the same reason, the $\mathrm{OH}$ torsion, $\tau \mathrm{OH}$, increases its frequency from $630 \mathrm{~cm}^{-1}$ in $\mathrm{H}$-fumarate to $1001 \mathrm{~cm}^{-1}$ in H-maleate. Further in-plane and out-of-plane vibrations of the anions are presented in Tables 1 and 2.

Choline bands were measured in some carboxylate choline liquids [20-22] or in systems where choline is weakly coupled with anions [67] and we find them substantially unchanged in our liquids. They are reported in Tables 1 and 2.

Table 1. Observed (IR and Raman) and calculated (B3LYP/6-311++G**) vibrational frequencies $\left[\mathrm{cm}^{-1}\right]$ [Ch][H-fumarate].

\begin{tabular}{|c|c|c|c|c|c|}
\hline Experiment & & Theory $[a]$ & & & Assignment $[b, c]$ \\
\hline IR & Raman & Frequency & $\begin{array}{l}\text { Intensity } \\
\text { IR }(\mathrm{km} / \mathrm{mol})\end{array}$ & $\begin{array}{l}\text { Intensity } \\
\text { Raman }\left(\AA^{4} / \mathbf{a m u}\right)\end{array}$ & \\
\hline 630 & & 572 & 78 & 1 & $\tau \mathrm{CO}$ \\
\hline 651 & & 620 & 97 & 3 & $\delta \mathrm{OCC}, \delta \mathrm{OCO}$ \\
\hline 750 & 716 & 723 & 21 & 9 & $\omega \mathrm{OCO}, \delta \mathrm{OCO}$ \\
\hline 796 & & 803 & 30 & 0 & $\omega \mathrm{OCO}$ \\
\hline 850 & 850 & 837 & 102 & 3 & $\tau \mathrm{CO}$ choline \\
\hline 920 & & 884 & 42 & 8 & $v \mathrm{CN}$ choline \\
\hline 954 & 960 & 980 & 31 & 5 & $\nu \mathrm{CN}$ choline \\
\hline 980 & & 1026 & 39 & 0 & $\gamma \mathrm{CH}$ \\
\hline 1085 & & 1101 & 55 & 3 & $v$ CO choline \\
\hline 1189 & & 1129 & 441 & 0 & $v \mathrm{CO}$ \\
\hline \multirow[t]{2}{*}{1251} & & 1237 & 64 & 7 & $\delta \mathrm{HCC}$ \\
\hline & 1277 & 1288 & 9 & 35 & $\delta \mathrm{HCC}$ \\
\hline 1292 & & 1355 & 122 & 4 & $\delta \mathrm{HCC}, \delta \mathrm{HOC}$ \\
\hline \multirow{2}{*}{1389} & 1384 & 1388 & 335 & 49 & $v \mathrm{CO}_{2}^{-}$sum \\
\hline & 1453 & 1492 & 59 & 33 & $\delta \mathrm{HCH}$ choline \\
\hline 1485 & & 1505,1498 & 44,48 & 3,11 & $\delta \mathrm{HCH}$ choline \\
\hline 1582 & 1580 & 1615 & 407 & 10 & $v \mathrm{CO}_{2}^{-}$asym \\
\hline 1637 & 1661 & 1698 & 50 & 332 & $v \mathrm{C}=\mathrm{C}$ \\
\hline 1706 & $\approx 1700$ & 1780 & 317 & 52 & $v \mathrm{C}=\mathrm{O}$ \\
\hline 2930 & 2938 & 3048,3030 & 36,115 & 115,169 & $v \mathrm{CH}_{3}$ choline \\
\hline \multirow{2}{*}{2980} & 2983 & 3069 & 114 & 350 & $v \mathrm{CH}_{2}$ choline \\
\hline & & $3164,3152,3148$ & $18,25,15$ & $62,71,83$ & $v \mathrm{CH}_{3}$ choline \\
\hline \multirow[t]{2}{*}{3036} & 3050 & & & & \\
\hline & & 3200,3180 & 0,2 & 32,55 & $v \mathrm{CH}$ \\
\hline
\end{tabular}

${ }^{[a]}$ Frequencies calculated for the ion pair. ${ }^{[b]}$ Frequency values shown in red represent bands assigned to the choline cation. ${ }^{[c]} v$, stretching; $\delta$, bending; $\tau$, torsion; $\omega$, wagging; $\rho$, rocking; $\gamma$, out-of-plane deformation. 
Table 2. Observed (IR and Raman) and calculated (B3LYP/6-311++G**) vibrational frequencies [ $\mathrm{cm}^{-1}$ ] [Ch][H-maleate].

\begin{tabular}{|c|c|c|c|c|c|}
\hline Experiment & & Theory $[a]$ & & & Assignment $[b, c]$ \\
\hline IR & Raman & Frequency & $\begin{array}{l}\text { Intensity } \\
\text { IR (km/mol) }\end{array}$ & $\begin{array}{l}\text { Intensity } \\
\text { Raman }\left(\AA^{4} / a m u\right)\end{array}$ & \\
\hline 594 & & 595 & 6 & 1 & $\omega \mathrm{OCO}, \tau \mathrm{CC}$ \\
\hline 664 & & 641 & 66 & 2 & $v \mathrm{CC}, \delta \mathrm{OCC}, \delta \mathrm{OCO}$ \\
\hline 734 & 716 & 744 & 10 & 14 & $v \mathrm{CN}$ choline \\
\hline 865 & 850 & 834 & 51 & 0 & $\tau \mathrm{CO}$ choline \\
\hline 910 & & 893 & 46 & 7 & $v \mathrm{CN}$ choline \\
\hline 961 & 960 & 950 & 24 & 1 & $\nu \mathrm{CN}$ choline \\
\hline 1001 & & 1039 & 70 & 2 & $\tau \mathrm{CO}$ \\
\hline 1050 & & 1035 & 24 & 2 & $\gamma \mathrm{CH}$ \\
\hline 1085 & & 1100 & 49 & 4 & $\nu \mathrm{CO}$ choline \\
\hline 1127 & 1136 & 1154 & 13 & 3 & $\rho \mathrm{CH} 3$ choline \\
\hline 1200 & & 1216 & 29 & 6 & $\rho \mathrm{CH} 3$ choline \\
\hline 1209 & 1222 & 1218 & 51 & 8 & $\delta \mathrm{HCC}$ \\
\hline 1361 & 1382 & 1368 & 153 & 49 & $v \mathrm{CO}_{2}^{-}$sym \\
\hline 1482 & 1460 & 1489,1517 & 85,49 & 10,1 & $\delta \mathrm{HOC}, \delta \mathrm{HCC}$ choline \\
\hline 1588 & & 1561 & 293 & 2 & $\delta \mathrm{HOC}$ \\
\hline \multirow[t]{2}{*}{$\approx 1580$} & & 1607 & 563 & 2 & $v \mathrm{CO}_{2}^{-}$asym \\
\hline & 1623 & 1669 & 112 & 126 & $\nu \mathrm{C}=\mathrm{C}$ \\
\hline \multirow[t]{2}{*}{1712} & 1694 & 1772 & 353 & 121 & $\nu \mathrm{C}=\mathrm{O}$ \\
\hline & $2680-2650$ & 2804 & 1495 & 46 & $v \mathrm{OH}$ \\
\hline 2930 & 2938 & 3033 & 117 & 226 & $v \mathrm{CH}_{3}$ choline \\
\hline \multirow[t]{2}{*}{2980} & 2983 & 3070,3076 & 8,20 & 132,170 & $\nu \mathrm{CH}_{2}$ choline \\
\hline & & 3160,3156 & 6,11 & 52,100 & $v \mathrm{CH}_{3}$ choline \\
\hline \multirow[t]{2}{*}{3036} & 3050 & & & & \\
\hline & & 3175,3154 & 12,0 & 155,50 & $v \mathrm{CH}$ \\
\hline
\end{tabular}

${ }^{[a]}$ Frequencies calculated for the ion pair. ${ }^{[b]}$ Frequency values shown in red represent bands assigned to the choline cation. ${ }^{[c]} v$, stretching; $\delta$, bending; $\tau$, torsion; $\rho$, rocking; $\gamma$, out-of-plane deformation.

\section{Conclusions}

The structure of two ionic liquids where the choline cation is coupled with two isomers of the monoanion of the maleic acid $\left(\mathrm{HOOCCH}=\mathrm{CHCOO}^{-}\right)$has been studied by energy-dispersive X-ray diffraction, IR and Raman spectroscopy and theoretical models. In the cis-conformation (H-maleate), the anion forms an intramolecular hydrogen bond that hinders the internal rotations of the $\mathrm{OH}$ group; this group is instead free to rotate in the trans-conformation (H-fumarate). Different theoretical models have been proposed to describe the liquids and the results have been compared with the experiments. Single ion pairs have been studied by DFT methods and small portions of the liquids have been modeled by AIMD methods and the results indicate that choline and anions are connected by hydrogen bonds. All calculations indicate that the choline cation prefers to connect mainly to the carboxylate group through $\mathrm{OH} \cdots \mathrm{O}$ interactions in both the compounds. Intermolecular bond distances are quite similar in the two systems, although the interaction energy is higher for H-fumarate. In this case, the negative charge is strictly localized on the $\mathrm{CO}_{2}^{-}$group and the electrostatic component of the interaction energy is therefore higher. MD simulations obtained with the GAFF force field confirm the cation anion distribution found with AIMD methods: the proton of choline is sharply localized around the oxygen atoms of the carboxylate groups and the $\mathrm{N}\left(\mathrm{CH}_{3}\right)_{3}^{+}$charged head of choline is oriented towards the negative portion of the anion. An intramolecular hydrogen bond of $\mathrm{H}$-maleate is found in the gas phase as well as in the liquid phase and its force is weakly affected by choline coordination. The trans-conformation of $\mathrm{H}$-fumarate allows further interactions between 
$\mathrm{COOH}$ and $\mathrm{CO}_{2}^{-}$of the anion and gives rise to correlations between anions in the radial distribution functions. No anion-anion correlation has been found for $\mathrm{H}$-maleate since intramolecular hydrogen bonding inhibits additional interactions between anions. The $X$-ray experimental pattern has been reproduced by MD simulations and structure functions and the complementary Diff( $r$ curves obtained by calculations are in good agreement with the X-ray experiments. IR and Raman spectra have been measured for both systems and some bands have been assigned on the basis of DFT frequency calculations. The vibrational stretching modes of the $\mathrm{CO}_{2}^{-}$group are quite similar in the two systems, revealing that the carboxylate group is perturbed similarly in both the anions. This is consistent with the structural features obtained from QM results that indicate very similar coupling geometries for both systems. The intramolecular hydrogen bond in $\mathrm{H}$-maleate is confirmed by the frequency of some vibrational motions, like $\mathrm{OH}$ group torsion or $\mathrm{OH}$ bending.

Supplementary Materials: The Supplementary Materials are available online. Figure S1. Photograph of the last prototype of EDXD diffractometer, with three detectors placed at three fixed angles; Table S1. Vibrational frequencies $\left[\mathrm{cm}^{-1}\right]$ calculated for the isolated and ion paired H-fumarate anion; Table S2. Vibrational frequencies $\left[\mathrm{cm}^{-1}\right]$ calculated for the isolated and ion paired $\mathrm{H}$-maleate anion.

Author Contributions: Conceptualization, F.R., S.D.M. and L.G.; methodology, F.R., S.D.M. and L.G.; sample preparation and IR measurements, F.F.; Raman measurements M.N. and P.B.; X-ray measurements, L.G.; computational investigation, S.D.M., F.R., F.F. and L.G.; writing-original draft preparation, F.R. and S.D.M. All authors have read and agreed to the published version of the manuscript.

Funding: This research received no external funding.

Conflicts of Interest: The authors declare no conflict of interest.

\section{References}

1. Graves, T.L.; Drummond, C.J. Protic Ionic Liquids: Properties and Applications. Chem. Rev. 2008, 108, 206-237. [CrossRef] [PubMed]

2. Wilkes, J.S. A short history of ionic liquids from molten salts to neoteric solvents. Green Chem. 2002, 4, 73-80. [CrossRef]

3. Lei, Z.; Chen, B.; Koo, Y.M. Introduction: Ionic Liquids. Chem. Rev. 2017, 117, 6633-6635. [CrossRef]

4. Angell, C.A.; Ansaria, Y.; Zhaoa, Z. Ionic liquids: Past, present and future. Faraday Discuss. 2012, 154, 9-27. [CrossRef] [PubMed]

5. Castner, E.W., Jr.; Wishart, J.F. Spotlight on ionic liquids. J. Chem. Phys. 2010, 132, 120901-120909. [CrossRef] [PubMed]

6. Wasserscheid, P.; Keim, W. Ionic Liquids-New "Solutions" for Transition Metal Catalysis. Angew. Chem. Int. Ed. 2000, 39, 3772-3789. [CrossRef]

7. Welton, T. Ionic liquids: A brief history. Biophys. Rev. 2018, 10, 691-706. [CrossRef]

8. Graves, T.L.; Drummond, C.J. Protic Ionic Liquids: Properties and Applications. Chem. Rev. 2015, 115, 11379-11448. [CrossRef]

9. Gathergood, N.; Scammells, P.J.; Garca, M.T. Biodegradable ionic liquids Part III. The first readily biodegradable ionic liquids. Green Chem. 2006, 8, 156-160. [CrossRef]

10. Petkovic, M.; Seddon, K.R.; Rebelo, L.P.N.; Pereira, C.S. Ionic liquids: A pathway to environmental acceptability. Chem. Soc. Rev. 2011, 40, 1383-1403. [CrossRef] [PubMed]

11. Fukaya, Y.; Iizuka, Y.; Sekikawa, K.; Ohno, H. Bio ionic liquids: Room temperature ionic liquids composed wholly of biomaterials. Green Chem. 2007, 9, 1155-1157. [CrossRef]

12. Fukumoto, K.; Yoshizawa, M.; Ohno, H. Room Temperature ionic Liquids from 20 Natural Amino Acids. J. Am. Chem. Soc. 2005, 127, 2398-2399. [CrossRef] [PubMed]

13. Fukumoto, K.; Ohno, H. Design and synthesis of hydrophobic and chiral anions from amino acids as precursor for functional ionic liquids. Chem. Comm. 2006, 3081-3083. [CrossRef] [PubMed]

14. Kagimoto, J.; Fukumoto, K.; Ohno, H. Effect of tetrabutylphosphonium cation on the physico-chemical properties of amino-acid ionic liquids. Chem. Comm. 2006, 2254-2256. [CrossRef]

15. Liu, Q.P.; Hou, X.D.; Li, N.; Zong, M.H. Ionic liquids from renewable biomaterials: Synthesis, characterization and application in the pretreatment of biomass. Green Chem. 2012, 14, 304-307. [CrossRef] 
16. Hou, X.D.; Liu, Q.P.; Smith, T. J.; Li, N.; Zong, M.H. Evaluation of Toxicity and Biodegradability of Cholinium Amino Acids Ionic Liquids. PLoS ONE 2013, 8, e59145. [CrossRef]

17. Pernak, J.; Syguda, A.; Mirska, I.; Pernak, A.; Nawrot, J.; Pradzynska, A.; Griffin, S.; Rogers, R.D. Choline-Derivative-Based Ionic Liquids. Chem. Eur. J. 2007, 13, 6817-6827. [CrossRef]

18. Muhammad, N.; Hossain, M.I.; Man, Z.; El-Harbawi, M.; Bustam, M.A.; Noaman, Y.A.; Alitheen, N.B.M.; Ng, M.K.; Hefter, G.; Yin, C.Y. Synthesis and Physical Properties of Choline Carboxylate Ionic Liquids. J. Chem. Eng. Data 2012, 57, 2191-2196. [CrossRef]

19. Gadilohar, B.L.; Shankarling, G.S. Choline based ionic liquids and their applications in organic transformation. J. Mol. Liq. 2017, 227, 234-261. [CrossRef]

20. Tanzi, L.; Benassi, P.; Nardone, M.; Ramondo, F. Choline salicylate ionic liquid by X-ray scattering, vibrational spectroscopy and molecular dynamics. J. Phys. Chem. A 2014, 118, 12229-12240. [CrossRef]

21. Tanzi, L.; Ramondo, F.; Caminiti, R.; Campetella, M.; Di Luca, A.; Gontrani, L. Structural studies on choline-carboxylate bio-ionic liquids by X-ray scattering and molecular dynamics. J. Chem. Phys. 2015, 143, 114506-114510. [CrossRef] [PubMed]

22. Tanzi, L.; Nardone, M.; Benassi, P.; Ramondo, F.; Caminiti, R.; Gontrani, L. Choline salicylate ionic liquid by X-ray scattering, vibrational spectroscopy and molecular dynamics. J. Mol. Liq. 2016, 218, 39-49. [CrossRef]

23. Benedetto, A.; Bodo, E.; Gontrani, L.; Ballone, P.; Caminiti, R. Amino acid anions in organic ionic compounds. An ab initio study of selected ion pairs. J. Phys. Chem. B 2014, 118, 2471-2486. [CrossRef] [PubMed]

24. Campetella, M.; Bodo, E.; Caminiti, R.; Martino, A.; D’Apuzzo, F.; Lupi, S.; Gontrani, L. Interaction and dynamics of ionic liquids based on choline and amino acid anions. J. Chem. Phys. 2015, 142, 234502-234510. [CrossRef]

25. Campetella, M.; Le Donne, A.; Daniele, M.; Gontrani, L.; Lupi, S.; Bodo, E.; Leonelli, F. Hydrogen Bonding as a Clustering Agent in Protic Ionic Liquids. Like-charge vs Opposite-charge dimers formation. J. Phys. Chem. B 2018, 122, 2635-2645. [CrossRef] [PubMed]

26. Gontrani, L. Choline-amino acid ionic liquids: Past and recent achievements about the structure and properties of these really "green" chemicals. Biophys. Rev. 2018, 10, 873-880. [CrossRef] [PubMed]

27. Perakis, F.; De Marco, L.; Shalit, A.; Tang, F.; Kann, Z.R.; Kühne T.D.; Torre, R.; Bonn, M.; Nagata, Y. Vibrational Spectroscopy and Dynamics of Water. Chem. Rev. 2016, 116, 7590-7607. [CrossRef]

28. Ojha, D.; Karhan, K.; Kühne, T.D. On the Hydrogen Bond Strength and Vibrational Spectroscopy of Liquid Water. Sci. Rep. 2018, 8, 16888-16895. [CrossRef]

29. Woo, H.K.; Wang, X.B.; Wang, L.S.; Lau, K.C. Probing the Low-Barrier Hydrogen Bond in Hydrogen Maleate in the Gas Phase: A Photoelectron Spectroscopy and ab Initio Study. J. Phys. Chem. A 2005, 109, 10633-10636. [CrossRef]

30. Fillaux, F.; Leygue, N.; Tomkinson, J.; Cousson, A.; Paulus, W. Structure and dynamics of the symmetric hydrogen bond in potassium hydrogen maleate: A neutron scattering study. Chem. Phys. 1999, 244, 387-403. [CrossRef]

31. Vener, M.V.; Manaev, A.V.; Tsirelson, V.G. Proton Dynamics in Strong (Short) Intramolecular H-Bond. DFT Study of the KH Maleate Crystal. J. Phys. Chem. A 2008, 112, 13628-13632. [CrossRef] [PubMed]

32. Vener, M.V.; Manaev, A.V.; Hadzi, D.; Tsirelson, V.G. QTAIM Study of Strong H-Bonds with the O-H $\cdots$ A Fragment $(\mathrm{A}=\mathrm{O}, \mathrm{N})$ in Three-Dimensional Periodical Crystals. Z. Phys. Chem. 2008, 222, 1349-1358. [CrossRef] [PubMed]

33. Carbone, M.; Caminiti, R.; Sadun, C. Structural study by energy dispersive X-ray diffraction of amorphous mixed hydroxycarbonates containing Co, Cu, Zn, Al. J. Mater. Chem. 1996, 6, 1709-1716. [CrossRef]

34. Caminiti, R.; Carbone, M.; Sadun, C. Palladium (II) and platinum (II) aqueous solutions. Evidence for the solvation of the $\left[\mathrm{PdCl}_{4}\right]_{2}^{-}$and $\left[\mathrm{PtCl}_{4}\right]_{2}^{-}$ions. J. Mol. Liq. 1998, 75, 149-158. [CrossRef]

35. Gontrani, L.; Caminiti, R.; Bencivenni, L.; Sadun, C. Molecular aggregation phenomena in solution: An energy dispersive X-ray diffraction study of concentrated imidazole water solutions. Chem. Phys. Lett. 1999, 301, 131-137. [CrossRef]

36. Gontrani, L.; Ramondo, F.; Caminiti, R. Energy dispersive X-ray diffraction and molecular dynamics meet: The structure of liquid pyrrole. Chem. Phys. Lett. 2006, 417, 200-205. [CrossRef]

37. Gontrani, L.; Ramondo, F.; Caracciolo, G.; Caminiti, R. A study of cyclohexane, piperidine and morpholine with X-ray diffraction and molecular simulations. J. Mol. Liq. 2008, 139, 23-28. [CrossRef] 
38. Gontrani, L.; Russina, O.; Marincola, F.C.; Caminiti, R. An energy dispersive x-ray scattering and molecular dynamics study of liquid dimethyl carbonate. J. Chem. Phys. 2009, 131, 244503-244509. [CrossRef] [PubMed]

39. Frisch, M.J.; Trucks, G.W.; Schlegel, H.B.; Scuseria, G.E.; Robb, M.A.; Cheeseman, J.R.; Scalmani, G.; Barone, V.; Mennucci, B.; Petersson, G.A.; et al. Gaussian 09, Revision C.01; Gaussian Inc.: Wallingford, CT, USA, 2010

40. Becke, A.D. Density-functional thermochemistry. III. The role of exact exchange. J. Chem. Phys. 1993, 98, 5648-5652. [CrossRef]

41. Lee, C.; Yang, W.; Parr, R. Development of the Colle-Salvetti correlation-energy formula into a functional of the electron density. Phys. Rev. B 1988, 37, 785-789. [CrossRef]

42. Jamroz, M. H. Vibrational Energy Distribution Analysis (VEDA): Scopes and limitations. Spectrochim. Acta Part A 2013, 114, 220-230. [CrossRef] [PubMed]

43. Tirado-Rives J.; Jorgensen, W.L. Performance of B3LYP Density Functional Methods for a Large Set of Organic Molecules J. Chem. Theory Comput. 2008, 4, 297-306. [CrossRef] [PubMed]

44. Liu, J.; He, X. Accurate prediction of energetic properties of ionic liquid clusters using a fragment-based quantum mechanical method. Phys. Chem. Chem. Phys. 2017, 19, 20657-20666. [CrossRef] [PubMed]

45. Kühne, T.D.; Iannuzzi, M.; Del Ben, M.; Rybkin, V.V.; Seewald, P.; Stein, F.; Laino, T.; Khaliullin, R.Z.; Schütt, O.; Schiffmann, F.; et al. CP2K: An electronic structure and molecular dynamics software packageQuickstep: Efficient and accurate electronic structure calculations. J. Chem. Phys. 2020, 152, 194103-194146. [CrossRef]

46. Becke, A.D. Density-functional exchange-energy approximation with correct asymptotic behavior. Phys. Rev. A 1988, 38, 3098-3100. [CrossRef] [PubMed]

47. Goedecker, S.; Teter, M.; Hutter, J. Separable dual-space Gaussian pseudopotentials. Phys. Rev. B 1996, 54, 1703-1710. [CrossRef]

48. Hartwigsen, C.; Goedecker, S.; Hutter, J. Relativistic separable dual-space Gaussian pseudopotentials from H to Rn. Phys. Rev. B 1998, 58, 3641-3662. [CrossRef]

49. Wang, J.; Wolf, R.; Caldwell, J.; Kollman, P.; Case, D. Development and testing of a general amber force field. J. Comput. Chem. 2004, 25, 1157-1174. [CrossRef]

50. Nosé, S. A unified formulation of the constant temperature molecular dynamics methods. J. Chem. Phys. 1984, 81, 511-519. [CrossRef]

51. Nosé, S. A molecular dynamics method for simulations in the canonical ensemble. Mol. Phys. 1984, 52, 255-268. [CrossRef]

52. Hoover, W.G. Canonical Dynamics: Equilibrium Phase-Space Distributions. Phys. Rev. A 1985, 31, $1695-1697$. [CrossRef] [PubMed]

53. Campetella, M.; Macchagodena, M.; Gontrani, L.; Kirchnen, B. Effect of alkyl chain length in protic ionic liquids: An AIMD perspective. Mol. Phys. 2017, 115, 1582-1589. [CrossRef]

54. Berendsen, H.J.C.; van der Spoen, D.; van Drunen, R. GROMACS: A message-passing parallel molecular dynamics implementation. Comput. Phys. Comm. 1995, 91, 43-56. [CrossRef]

55. Dupradeau, F.Y.; Pigache, A.; Zaffran, T.; Savineau, C.; Lelong, R.; Grivel, N.; Lelong, D.; Rosanski, W.; Cieplak, P. The R.E.D. tools: Advances in RESP and ESP charge derivation and force field library building. Phys. Chem. Chem. Phys. 2010, 12, 7821-7839. [CrossRef]

56. Cornell, W.D.; Cieplak, P.; Bayly, C.I.; Gould, I.R.; Merz, K.M., Jr.; Ferguson, D.M.; Spellmeyer, D.C.; Fox, T.; Caldwell, J.W.; Kollman, P.A. A Second Generation Force Field for the Simulation of Proteins, Nucleic Acids, and Organic Molecules. J. Am. Chem. Soc. 1995, 117, 5179-5197. [CrossRef]

57. Hess, B.; Bekker, H.; Berendsen, H.J.C.; Fraajie, J.G.E.M. LINCS: A linear constraint solver for molecular simulations. J. Comput. Chem. 1997, 18, 1463-1472. [CrossRef]

58. Case, D.A.; Ben-Shalom, I.Y.; Brozell, S.R.; Cerutti, D.S.; Cheatham, T.E., III; Cruzeiro, V.W.D.; Darden, T.A.; Duke R.E.; Ghoreishi, D.; Gilson, M.K.; et al. AMBER 2018; University of California: San Francisco, CA, USA, 2018.

59. Martinez, L.; Antrade, R.; Birgin, E.G.; Martinez, J.M. PACKMOL: A package for building initial configurations for molecular dynamics simulations. J. Comput. Chem. 2009, 30, 2157-2164. [CrossRef]

60. Brehm, M.; Kirchner, B. TRAVIS-A Free Analyzer and Visualizer for Monte Carlo and Molecular Dynamics Trajectories. J. Chem. Inf. Model. 2011, 51, 2007-2023. [CrossRef] 
61. Hollòczki, O.; Macchiagodena, M.; Weber, H.; Thomas, M.; Brehm, M.; Stark, A.; Russina, O.; Triolo, A.; Kirchner, B. Triphilic Ionic-Liquid Mixtures: Fluorinated and Non-fluorinated Aprotic Ionic-Liquid Mixtures. ChemPhysChem 2015, 16, 3325-3333. [CrossRef]

62. Viloca, M.G.; Gonzales-Lafont, A.; Lluch, J.M. Theoretical Study of the Low-Barrier Hydrogen Bond in the Hydrogen Maleate Anion in the Gas Phase. Comparison with Normal Hydrogen Bonds. J. Am. Chem. Soc. 1997, 119, 1081-1086. [CrossRef]

63. Xi Tian, S.; Li, H.B. A theoretical study of the photodetachment and intramolecular hydrogen-bonding energies of hydrogen maleate anions. J. Phys. Chem. A 2007, 111, 4404-4410. [CrossRef] [PubMed]

64. Gontrani, L.; Bodo, E.; Triolo, A.; Leonelli, F.; D'Angelo, P.; Migliorati, V.; Caminiti, R. The interpretation of diffraction patterns of Protic Ionic Liquids: A challenging task for classical molecular dynamics simulations. J. Phys. Chem. B 2012, 116, 13024-13032. [CrossRef]

65. Ramondo, F.; Gontrani, L.; Campetella, M. Coupled hydroxyl and ether functionalisation in EAN derivatives: The effect of hydrogen bond donor/acceptor groups on the structural heterogeneity studied with X-ray diffractions and fixed charge/polarizable simulations. Phys. Chem. Chem. Phys. 2019, 21, 11464-11475. [CrossRef]

66. Andersson, M.P.; Uvdal, P. New Scale Factors for Harmonic Vibrational Frequencies Using the B3LYP Density Functional Method with the Triple-z Basis Set 6-311+G(d,p). J. Phys. Chem. A 2005, 109, 12, 2937-2941. [CrossRef] [PubMed]

67. Pohle, W.; Gauger, D.R.; Fritzsche, H.; Rattay, B.; Selle, C.; Binder, H.; Bohlig, H. FTIR-spectroscopic characterization of phosphocholine-headgroup model compounds. J. Mol. Struct. 2001, 563-564, 463-467. [CrossRef]

Publisher's Note: MDPI stays neutral with regard to jurisdictional claims in published maps and institutional affiliations. 